\title{
Development of a Two-Phase Model for the Hot Deformation of Highly-Alloyed Aluminum DE-FC07-01ID14190
}

\author{
A. J. Beaudoin ${ }^{1}$, J. A. Dantzig ${ }^{1} \&$ I. M. Robertson ${ }^{2}$ (Co-PIs) \\ B. E. Gore ${ }^{2}$, S. F. Harnish ${ }^{1} \&$ H. A. Padilla ${ }^{1}$ (graduate students) \\ ${ }^{1}$ Department of Mechanical and Industrial Engineering \\ ${ }^{2}$ Department of Materials Science and Engineering \\ University of Illinois, Urbana, IL 61801, USA
}

October 31, 2005 


\section{Executive Summary}

Conventional processing methods for highly alloyed aluminum consist of ingot casting, followed by hot rolling and thermal treatments. Highly alloyed metals are more susceptible to the development of defects in hot rolling, due to localized melting along the chemistry rich grain boundaries. Defects result in lost productivity and wasted energy through the need to re-melt and reprocess the material. Improved quality and yield for both conventional hot rolling and continuous casting will be achieved only through understanding of the flow of the alloyed aluminum at temperatures approaching the melting point.

This research centers on developing a fundamental understanding for deformation of wrought 705X series alloys, a key alloy system used in structural airframe applications. Emphasis is given to study at the higher temperatures encountered in the industrial hot working regime. The development of damage at grain boundaries is characterized through a novel test that provides initiation of a failure while preserving a controlled deformation response. Data from these mechanical tests are linked to computer simulations of the hot rolling process through a critical measure of damage. Relations for rate-dependent flow stress, also used in the computer simulations, are developed through the mechanical tests. Transmission electron microscopy provides fundamental insight into deformation at these high working temperatures, and - in a novel link between microscale and macroscale response - the evolution of microstructure (crystallographic orientation) provides feedback for tuning of friction in the hot rolling process.

The key product of this research is a modeling framework for the analysis of industrial hot rolling. The framework is built upon codes that are readily available: the commercial code FIDAP and the Viscoplastic Self-Consistent (VPSC) model. The use of these codes provides for a sound engineering platform that may be applied with practical utility in an industrial setting. 


\section{Accomplishments}

- A novel experimental test has been developed for the study of failure initiated at grain boundaries in hot deformation. While use in the present work is restricted to alloys of the AA 705X series, the test would provide for the general study of "hot short" defects in aluminum alloys.

- The interactions of dislocations with precipitates is examined with in situ TEM.

- A methodology is set forth for the tuning of friction in hot rolling. Specifically, friction may be assymetrically tuned between work rolls and the slab based upon agreement with predicted and measured crystallographic texture.

- The modeling framework is built upon a computational platform that is widely available, providing a tool for practical application in industry.

- The work has resulted in two peer-reviewed publications, two student theses, and two conference proceedings. There have been numerous presentations at technical conferences, national laboratories and both research and production facilities of our industrial collaborator (ALCOA). 


\section{Project Summary}

The following project summary is drawn from the publications authored as a result of this research $[1,2]$.

\subsection{Introduction}

Highly alloyed aluminum has been one of the most widely successful and broadly applicable materials developed for engineering structures in the last century. Industries which have benefited from the development of these alloys include packaging, automotive, and aerospace. The Al-Zn-Mg-Cu 7000 series alloys have seen extensive use in the aerospace industry. The 705X alloys, which exhibit both a high fracture toughness and high resistance to stress corrosion cracking when brought to a T7 temper, were specifically developed to be used in plate form for structural wing components in commercial aircraft [3].

Fabrication of these products begins with direct chill (DC) casting followed by heat treatment for homogenization. The slabs are then taken from the solution treatment furnace, and hot rolled through several passes until the desired final thickness is achieved. The rolled material is then quenched and stretched. In the final step, the plate is aged to precipitate the strengthening phases. The thermomechanical history in these processes produces throughthickness gradients in constituent phase and precipitate distributions, texture, and grain structure, which all lead to gradients in mechanical properties. Detailed review and study of the relationship between microstructure, strength and toughness in aged 7050 plate, with consideration of anisotropy, has been given by Dumont et al. [4]. It is desirable to look further upstream and define the thermomechanical processing window (TPW), i.e. the range of physically realizable processing parameters (roll speed, lay-on temperature, reduction, lubricant properties, etc.) which lead to production of a quality product.

To gain a better understanding of the limits of the TPW and what microstructural processes govern the material behavior near those limits, experiments and numerical simulations have been performed. Material characterization studies under different temperature and stress histories provide understanding of the precipitate and second phase structure, and indicate active deformation mechanisms. Guided by these results, and industrial practice, a homogenization procedure is developed and used to prepare samples for mechanical testing. A novel test procedure is also introduced, which permits identifying the onset of damage. The mechanical test data are then used to develop constitutive relations appropriate for hot rolling. We pose a rolling model through introduction of the constitutive relations into established procedures for finite element analysis of viscoplastic flow, with subsequent postprocessing of material history along streamlines to predict evolution of crystallographic texture in the final product. A contribution of this modeling effort lies in the tuning of boundary conditions for friction so as to establish agreement between measured and predicted gradients in crystallographic texture. To complete the structure-properties-processing triangle, we interpret simulation results on the basis of the experimental conditions associated with damage initiation. 


\subsection{Material characterization}

\subsubsection{TEM studies}

In order to understand the mechanical behavior of AA 705X under hot rolling conditions, it is essential to identify the phases present as a function of various thermal histories. To this end, the microstructure of hot-rolled 7055 was examined in the as-received state (T79), after a heat treatment in which sections of the plate were first homogenized at $480^{\circ} \mathrm{C}$ for one hour, then held at temperatures of $500^{\circ} \mathrm{C}, 460^{\circ} \mathrm{C}$, or $420^{\circ} \mathrm{C}$ for three minutes, and then quenched. TEM samples were prepared using conventional techniques, and were then examined in a JEOL 4000 at an operation voltage of $300 \mathrm{keV}$.

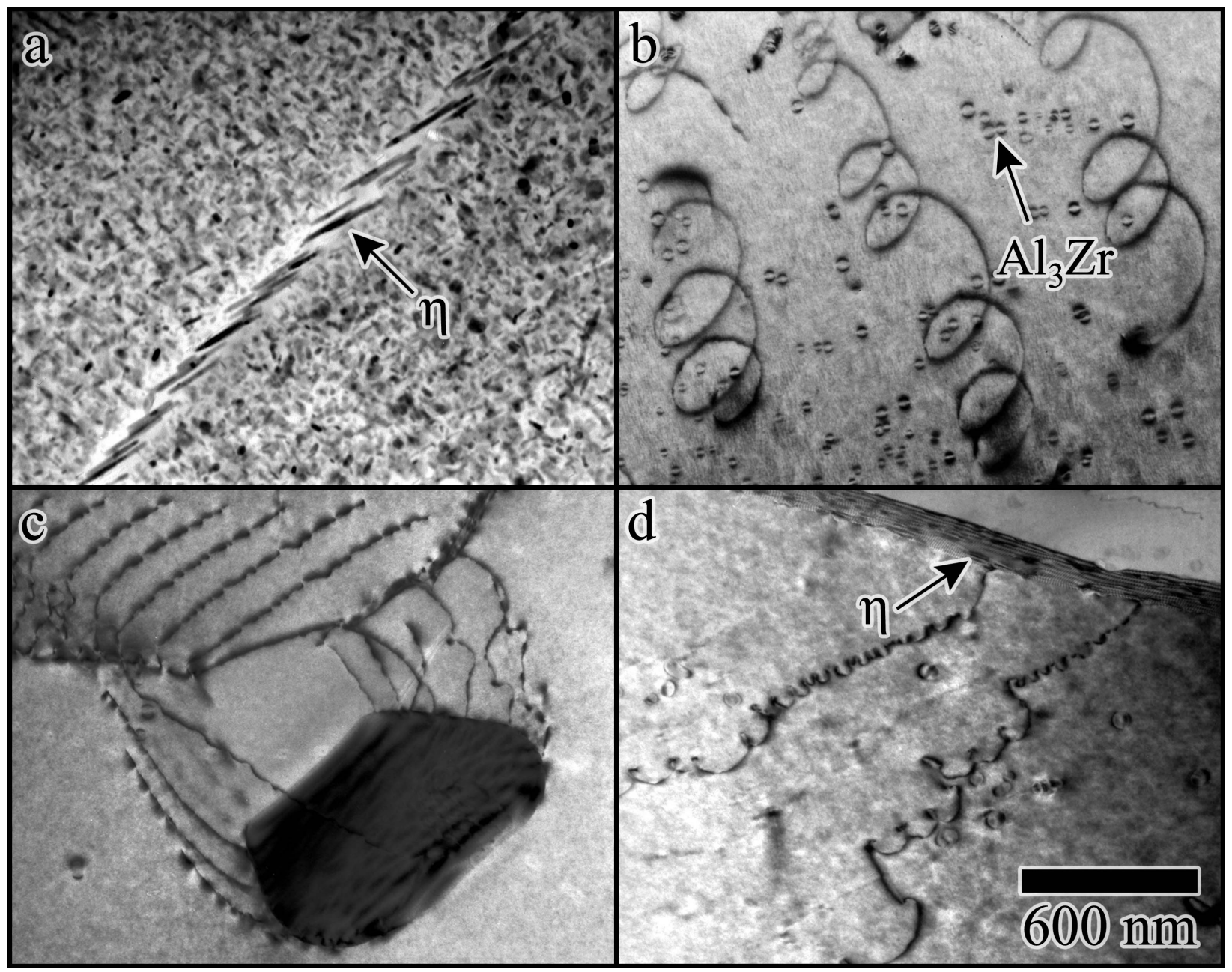

Figure 1: Microstructures of AA7055: (a) in the as-received T79 condition; and after homogenizing at $480^{\circ} \mathrm{C}$ for one hour, then holding for three minutes at (b) $500^{\circ} \mathrm{C}$, (c) $460^{\circ} \mathrm{C}$, and (d) $420^{\circ} \mathrm{C}$ respectively, and then quenching in water. Dislocations evident in the micrographs are due to residual strain fields in the samples. 
The as-received microstructure, shown in Figure 1(a), consisted of elongated particles of the strengthening $\eta$-phase $\left(\mathrm{MgZn}_{2}\right)$ throughout the matrix and along the grain boundaries, with smaller particles of $\eta^{\prime}$ strengthening phase in the matrix. In addition, coherent $\mathrm{Al}_{3} \mathrm{Zr}$ precipitates (20-50 nm), which hinder recrystallization, are distributed throughout the matrix [5]. While the $\mathrm{Al}_{3} \mathrm{Zr}$ precipitates are stable at high temperature due to their high melting point $\left(\sim 1500^{\circ} \mathrm{C}\right)$, the $\eta$-type particles can be put back into solution via heat treatment at $480^{\circ} \mathrm{C}$. An example of such a homogenized microstructure is shown in Figure 1(b); here the sample has been solutionized, and then quenched after a three minute hold at $500^{\circ} \mathrm{C}$. As would be expected, the microstructure is free of all precipitates and contains only $\mathrm{Al}_{3} \mathrm{Zr}$ precipitates. The helical dislocations in this image are a result of a climb-assisted process due to the supersaturation of vacancies retained during the quench from high temperatures. Figures 1(c) and 1(d) show microstructures obtained after first cooling to, and then quenching from, $460^{\circ} \mathrm{C}$ and $420^{\circ} \mathrm{C}$, respectively. In Figure $1(\mathrm{c})$, the microstructure is still free of $\eta$ type particles; however large constituent phases (such as $\mathrm{Al}_{7} \mathrm{Cu}_{2} \mathrm{Fe}$ ) have formed and, as shown, interact with the dislocations at sub-grain boundaries. This dislocation structure suggests that this sub-grain boundary was mobile at the homogenization temperature [6]. As the holding temperature is lowered further, $\eta$ particles begin to re-precipitate, nucleating preferentially at dislocations and on $\mathrm{Al}_{3} \mathrm{Zr}$ particles. As an example, the arrow in $1(\mathrm{~d})$ highlights $\eta$ particles nucleating on the dislocations in a grain boundary. These results correlate well with differential scanning calorimetry analysis. A temperature of $480^{\circ} \mathrm{C}$ is sufficient to dissolve the strengthening phases. This provides a basis for the homogenization procedure employed in mechanical testing, to be described below. Although an example is not shown here, cooling to lower temperatures $\left(\simeq 380^{\circ} \mathrm{C}\right)$ increases the number and size of the $\eta$ particles.

In-situ TEM straining experiments allow direct observation of the interaction of dislocations with precipitates as a function of temperature. Information gained provides guidance in selection (and improvement) of material models for predicting the bulk deformation behavior of particle-strengthened aluminum alloys. Initially, in-situ TEM deformation of AA705X was performed at temperatures approaching $480^{\circ} \mathrm{C}$ to minimize the volume fraction of secondphase particles. This enabled clearer observation of the dislocation-particle interactions. Preliminary in-situ experiments revealed an attractive interaction between matrix dislocations and the semi-coherent $\eta$ particles, a direct interaction between the matrix dislocation and the particle-matrix interface, and a rate-limiting detachment step. In Figure 2, a series of images taken during deformation at $475^{\circ} \mathrm{C}$ shows a typical dislocation- $\eta$ interaction in AA705X [2]. In this figure, the strength of the interaction can be seen in 1c where the detachment angle is approximately 90 degrees for both dislocation segments. This configuration is typical of departure-side pinning and is commonly associated with a strong attractive interaction.

Because of the complex kinetics of the AA705X system, a simpler Al-Mg-Sc alloy with semi-coherent $\mathrm{Al}_{3} \mathrm{Sc}$ particles was chosen in order to further study these dislocation-particle interactions. An ingot of Al-4Mg-0.3Sc was obtained from Kaiser Aluminum in the as-cast condition. It was then homogenized at $575^{\circ} \mathrm{C}$, quenched, and annealed at $280^{\circ} \mathrm{C}$ for 8 hrs. 


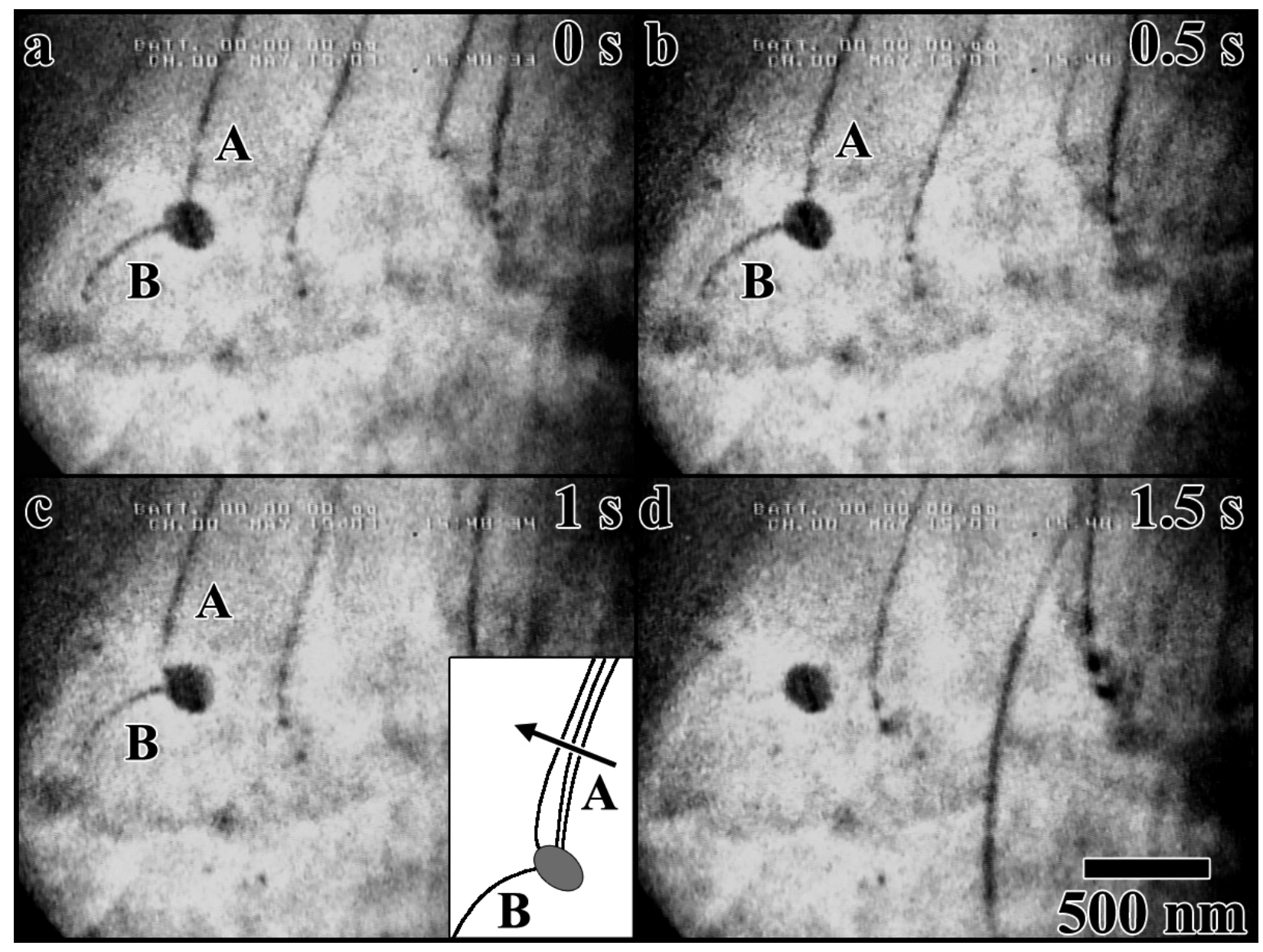

Figure 2: Interaction of a dislocation with an $\eta\left(\mathrm{MgZn}_{2}\right)$ particle in AA705X at $475^{\circ} \mathrm{C}$ showing departure-side pinning. The schematic shows the motion of the dislocation in (a)(c). 
TEM samples were prepared using conventional techniques, and were then examined in a JEOL 4000 at an operation voltage of either 200 or $300 \mathrm{keV}$.

In-situ straining experiments revealed an attractive interaction between matrix dislocations and the semi-coherent $\mathrm{Al}_{3} \mathrm{Sc}$ particles, similar to the interaction above for the AA705X alloy. An example is shown in Figure 3, where a series of images captured from individual videotape frames illustrate the attractive interaction of a mobile lattice dislocation with a large $\mathrm{Al}_{3} \mathrm{Sc}$ particle at approximately $400^{\circ} \mathrm{C}$ [2]. The dislocation is indicated by the arrows in Figure 3a and 3b and is narrowly inclined with respect to the electron beam. The initial dislocation velocity under a constant straining stage displacement rate was $30 \mathrm{~nm} \cdot \mathrm{s}^{-1}$. With no increase in displacement rate, the dislocation velocity increased by a factor of three to about $100 \mathrm{~nm} \cdot \mathrm{s}^{-1}$ as the dislocation approached within $100 \mathrm{~nm}$ of the particle, Figures $3 \mathrm{~b}$ and 3c. The capture of the dislocation by the precipitate can be seen in Figure 2c, with the remaining segment indicated by the arrow. Evidence that the dislocation is interacting with the particle comes from the changes in the Moiré fringe pattern seen in Figures 3d-f. The total interaction time is 60 seconds with the majority (40 seconds) being associated with the detachment of the dislocation from the precipitate. Thus the rate-limiting step of the interaction is detachment.

In addition to a strong attractive interaction of the dislocation to the particle, repulsive interactions are also observed. An example of this duality is shown in Figure 4 for dislocations interacting with a single $\mathrm{Al}_{3} \mathrm{Sc}$ particle at an approximate temperature of $400^{\circ} \mathrm{C}[2]$. A schematic of the interactions, in which dotted lines indicate the slip traces on the sample surface, is given for further clarification with the letters corresponding to the labels on the images. As dislocation 2 approaches the particle, a small segment of its line length interacts with the top portion of the particle-matrix interface as indicated by the arrow in Figure 4c. Dislocation segment $2 \mathrm{~b}$ then experiences a strong repulsive force and is pushed away from the particle in Figure 4d. The interacting segment remains pinned to the interface, perhaps due to interactions with interfacial dislocations, and the remaining free segment, 2a, continues to move slowly along its original path. Two seconds later, a segment of dislocation 3 experiences a noticeable attractive interaction with the bottom side of the particle, which is shown with an arrow in Figure 4f. Dislocations 2 and 3 appear to be on parallel slip planes, and are likely identical in character, indicating that the position where the dislocation strikes the particles influences the interaction.

The attractive and repulsive interactions between the dislocation and the particle presented in Figures 2, 3 and 4 can be attributed to the difference in lattice parameter, shear modulus, coefficient of thermal expansion, and Poisson's ratio between the particle and the matrix. Based on these differences, the interaction force between an edge dislocation and a particle can be calculated using linear elasticity theory. The glide force experienced by an edge dislocation as a function of the ratio of the distance from the slip plane to the particle center line $(H)$ to the particle radius $(R)$ for an $\mathrm{Al}_{3} \mathrm{Sc}$ particle in an $\mathrm{Al}$ matrix at $400^{\circ} \mathrm{C}$ is shown in Figure 5 [2]. The inset illustrates the geometry and parameters used for this calculation. Input values for the lattice parameter, shear modulus, coefficient of thermal expansion, and Poisson's ratio were, respectively, $0.4103 \mathrm{~nm}[7,8], 68.4 \mathrm{GPa}[9], 16 \times 10^{-6} / \mathrm{K}$ [10], 


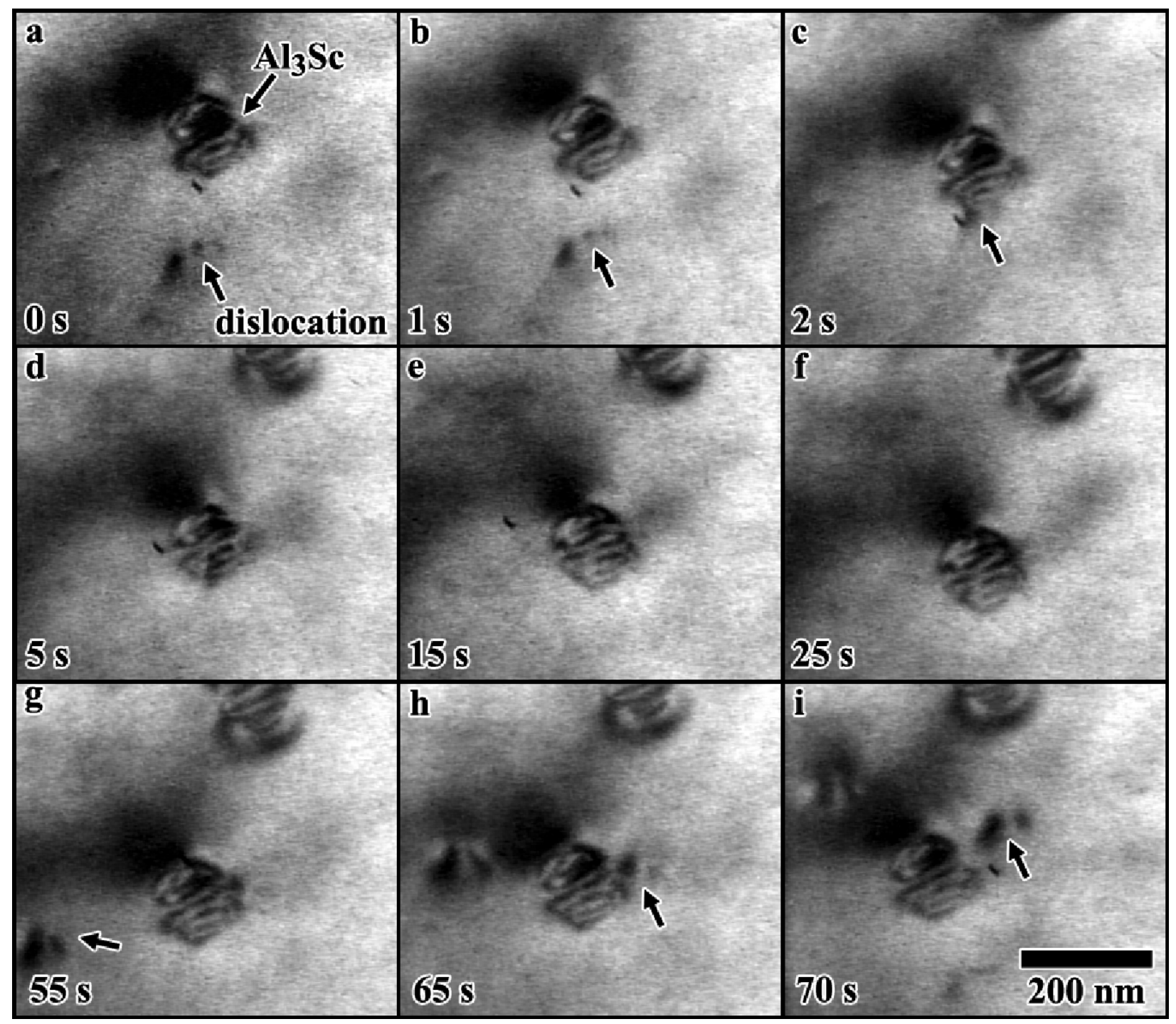

Figure 3: Attractive interaction between a matrix dislocation and an $\mathrm{Al}_{3} \mathrm{Sc}$ precipitate at $400^{\circ} \mathrm{C}$ 


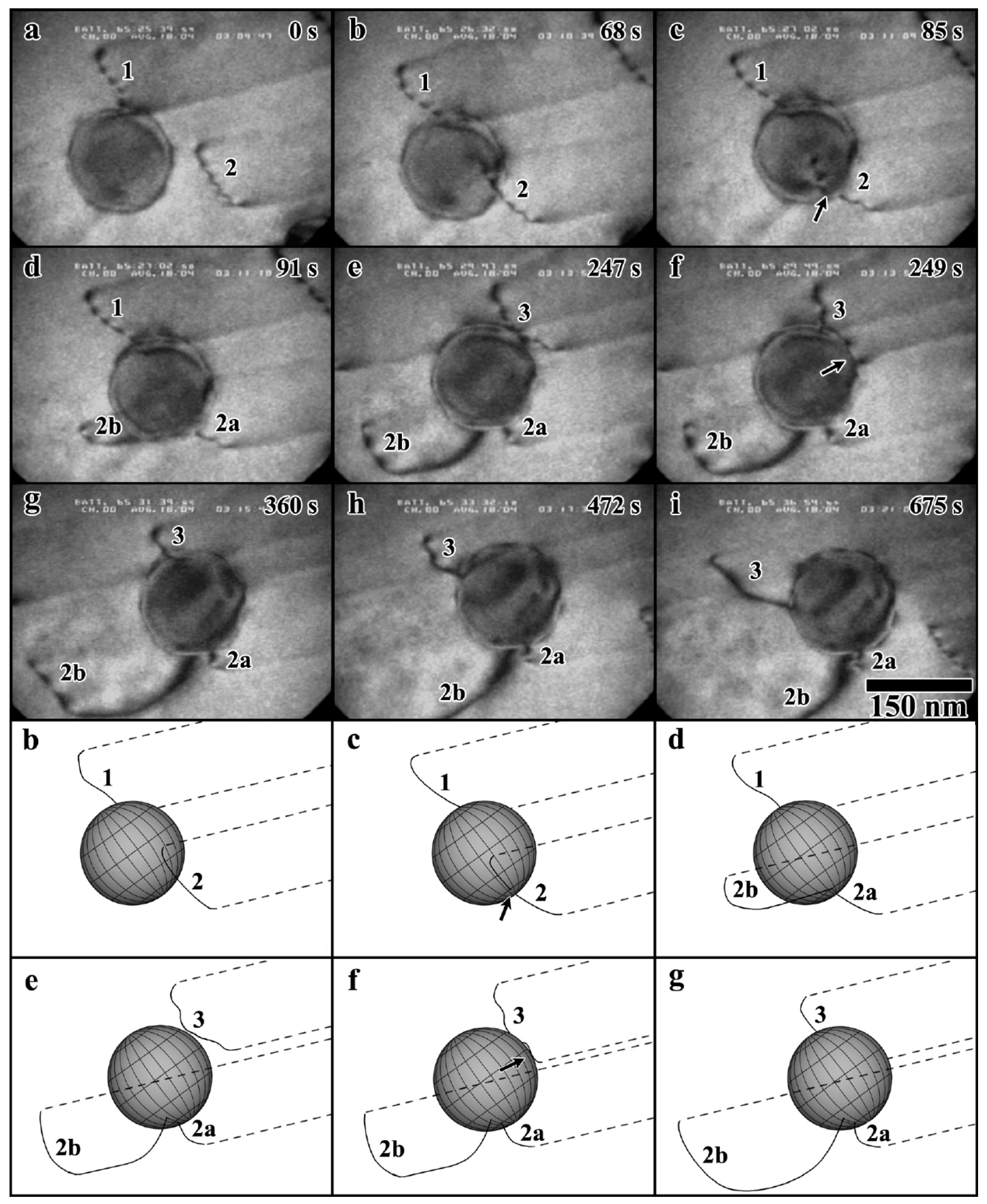

Figure 4: Attractive (dislocation 3) and repulsive (dislocation 2) interactions of dislocations interacting with the same $\mathrm{Al}_{3} \mathrm{Sc}$ particle at $400^{\circ} \mathrm{C}$ 
and 0.201 [9] for the $\mathrm{Al}_{3} \mathrm{Sc}$, and $0.4049 \mathrm{~nm}$ [11], $26 \mathrm{GPa}$ [12], $23.4 \times 10^{-6} / \mathrm{K}$ [12], 0.33 [12] for the $\mathrm{Al}$ matrix. In addition to a strong attractive interaction for $H / R>0$, the theory also predicts a strong repulsive interaction for $H / R<0$, which is consistent with previous observations.

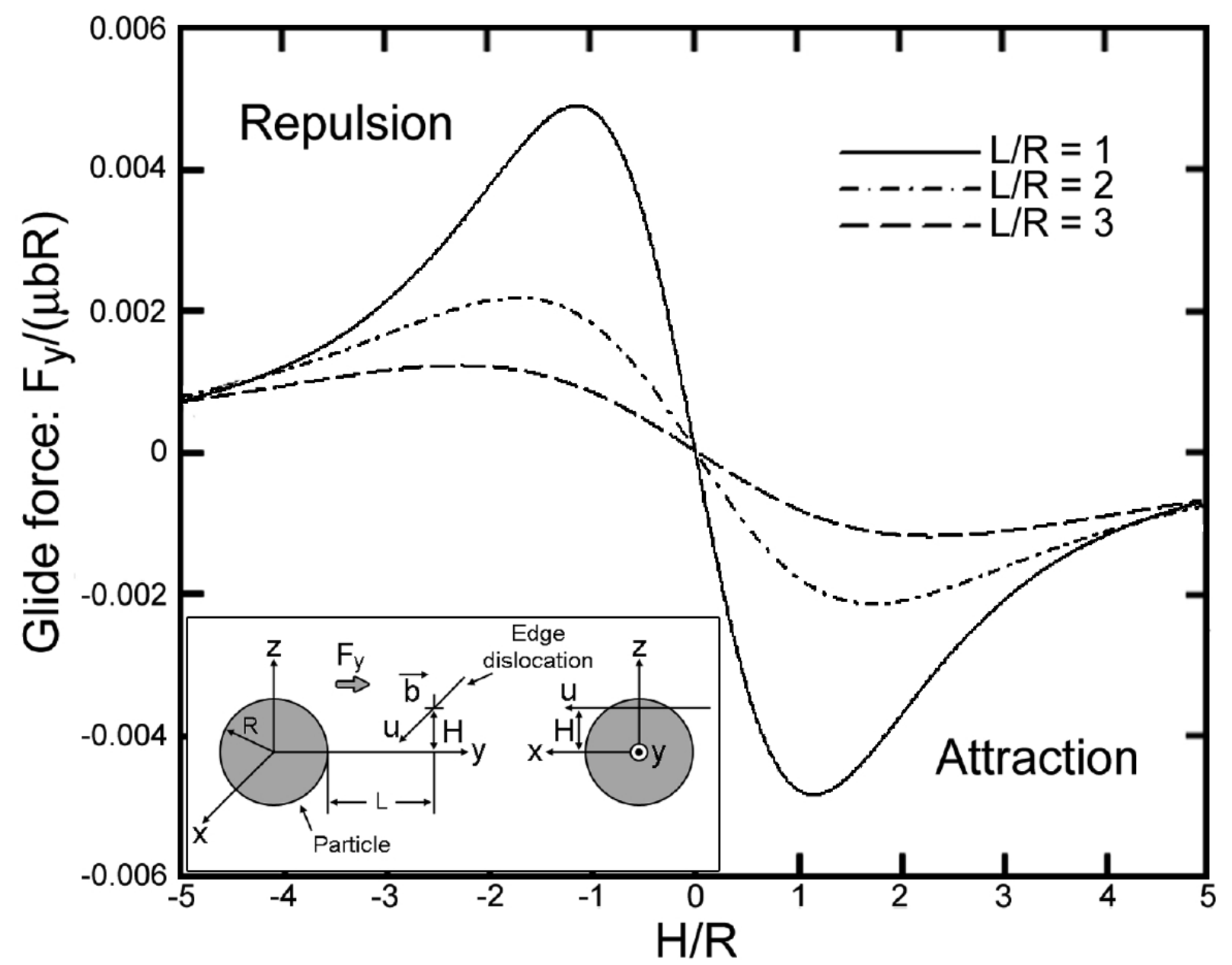

Figure 5: Linear elastic description of the glide force acting on an edge dislocation as it approaches an $\mathrm{Al}_{3} \mathrm{Sc}$ particle in an $\mathrm{Al}$ matrix at $400^{\circ} \mathrm{C}$

It was also found that the matrix dislocation interacts directly with the particle-matrix interface. This can be seen in Figure 6 which shows a sub-grain boundary (array of dislocations) interacting with a single $\mathrm{Al}_{3} \mathrm{Sc}$ at $400^{\circ} \mathrm{C}$ [2]. The sample had previously been rolled to a $70 \%$ reduction and then deformed at $460^{\circ} \mathrm{C}$ at a strain rate of $10^{-3} \mathrm{~s}^{-1}$ to a true strain of 0.2 By comparison of the initial and final images of the particle, $6 \mathrm{a}$ and $6 \mathrm{f}$, it is clear that the contrast fringes at the interface have rotated. This rotation is due to a change in the interfacial strain, which arises due to changes in the interfacial structure. It is likely that the matrix 
dislocations dissociate into interfacial dislocations at the particle-matrix interface and then interact with existing interfacial dislocations during the bypass process. This would give rise to the altered interfacial structure and also account for the rate-limiting detachment step as the initial matrix dislocation must be reconstructed from the interfacial dislocations at the detachment point. The altered interfacial structure may also influence future interactions, and so should be taken into consideration in the development of a continuum model.

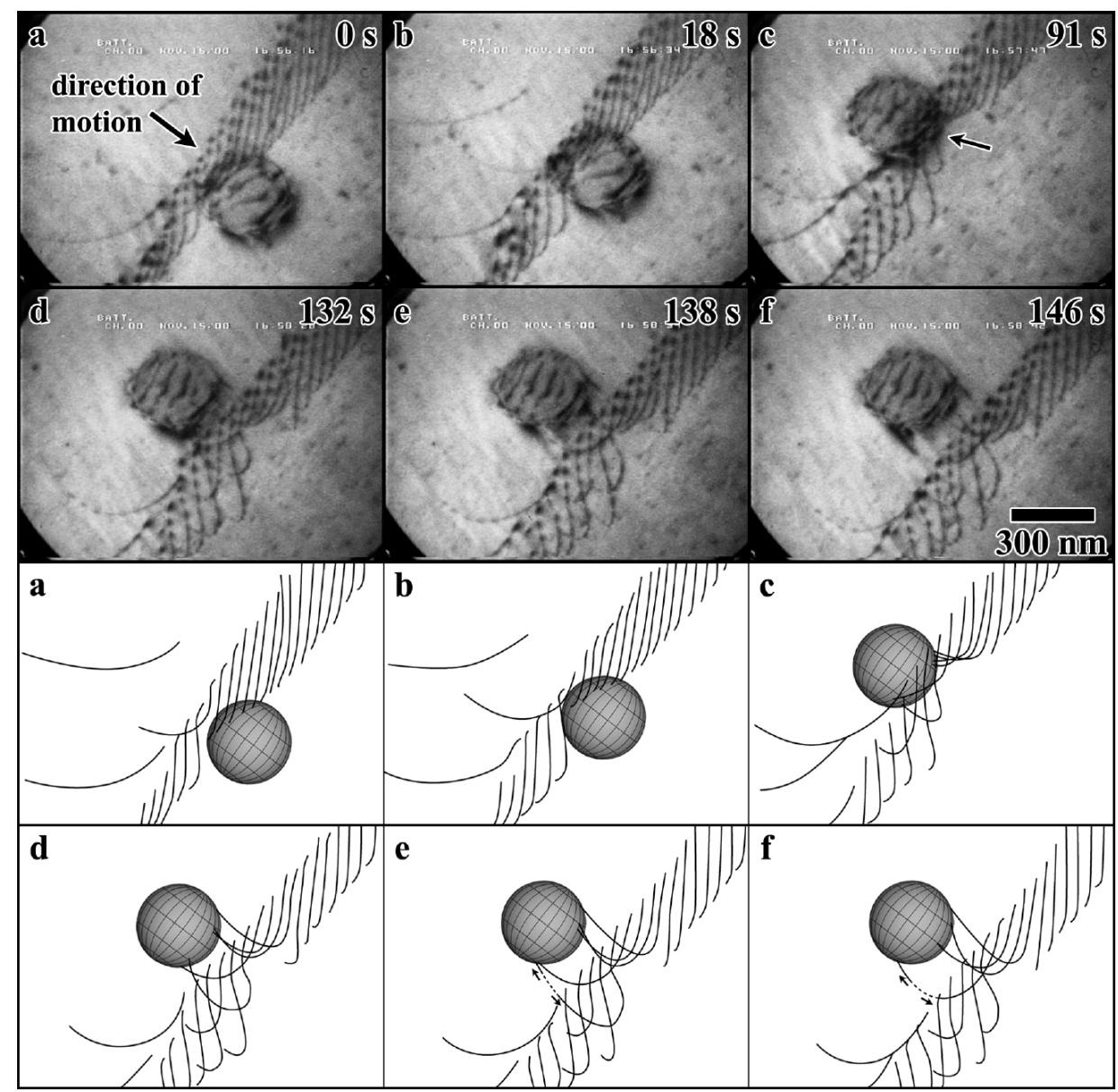

Figure 6: Interaction of a subboundary with $\mathrm{Al}_{3} \mathrm{Sc}$ at $400^{\circ} \mathrm{C}$

. Rotation of the contrast fringes on the particle indicates a change in interfacial strain.

Schematics show the details of the interaction.

\subsubsection{Crystallographic texture}

Insight into the thermomechanical processing history of the as-received material can be gained from examination of texture gradients through the plate thickness. Roll gap geometry in plate rolling, combined with frictional effects induced by the work rolls, promotes a nonuniform deformation field. Away from the center-plane, shear deformations are developed 
as a consequence of boundary conditions [13]. Studies of rolling with high reduction ratio show the $45^{\circ}$ ND-rotated cube, $\{001\}\langle 110\rangle$ as a dominant component of the texture in regions of high shear [14]. Combined experiment and finite element simulation have shown the position of maximum shear texture development to lie $80 \%$ of the distance from the centerline to the surface [15]. Such gradients in texture have been observed in 7010 plate, with the centerline bearing components typical of plane strain compression and, closer to the surface, a transition to a texture with $\{001\}\langle 110\rangle$ as the dominant component [16].

Slices preserving the normal direction (ND) were taken from $25 \mathrm{~mm}$ thick plate, and experimental texture measurements were made on the top, middle (t/2), bottom, and quarterthickness planes (t/4 and 3t/4). The surface of each plane was polished with $3 \mu \mathrm{m}$ alumina slurry and electro-etched in a solution of $25 \%$ nitric acid in methanol at a temperature of $-25^{\circ} \mathrm{C}$ and a voltage of $10 \mathrm{~V}$. Texture was measured through electron backscattered pattern (EBSP) analysis, which was performed using Oxford Instruments software on a Zeiss DSM960 SEM. $\langle 111\rangle$ pole figures calculated from these experiments are shown as stereographic projections in Figure 7.

Of particular note is the asymmetry in the texture of the top and bottom surfaces. The bottom surface shows a much stronger ND rotated cube shear texture compared to the top surface. The asymmetry is also evident in the texture at the quarter planes. The midplane, as expected, is representative of plane-strain compression deformation. The asymmetry in the experimental texture suggests a corresponding asymmetry in the rolling process. This has important implications for the development of our numerical model of the rolling process, which must be able to capture this asymmetry.

Given our focus on hot rolling, comment on the relevance of texture for as-received plate to that developed relatively early in thermomechanical history for the product is warranted. In a detailed study of 7010 plate, Engler et al. [16] provide evidence that the recrystallized texture contains a random component associated with particle stimulated nucleation (PSN), while recovery of subgrain structure tends to sharpen the original deformation texture. As indicated above, Zr addition to the alloy suppresses development of recrystallization components. The net effect is that for our material, the bulk texture developed in hot rolling and final texture following solution heat treatment are quite similar. The occurrence of PSN is also indicated in 7050 plate [4]. From the standpoint of the current effort, this is a fortuitous circumstance: comparison of measured crystallographic texture from the final product with simulated texture is possible by virtue of this mechanism of texture preservation. We return to this point in the section on the hot rolling model, after first describing the development of a constitutive model for hot deformation.

\subsection{Mechanical testing}

A mechanical testing program was undertaken to develop constitutive relations suitable for modeling hot rolling. We performed uniaxial compression tests on samples following a thermomechanical protocol similar to the industrial process. The testing apparatus and specimen geometry are shown schematically in Figure 8. The tests were performed in a hydraulic load frame with Instron 8500 controls. Temperature control was effected using 

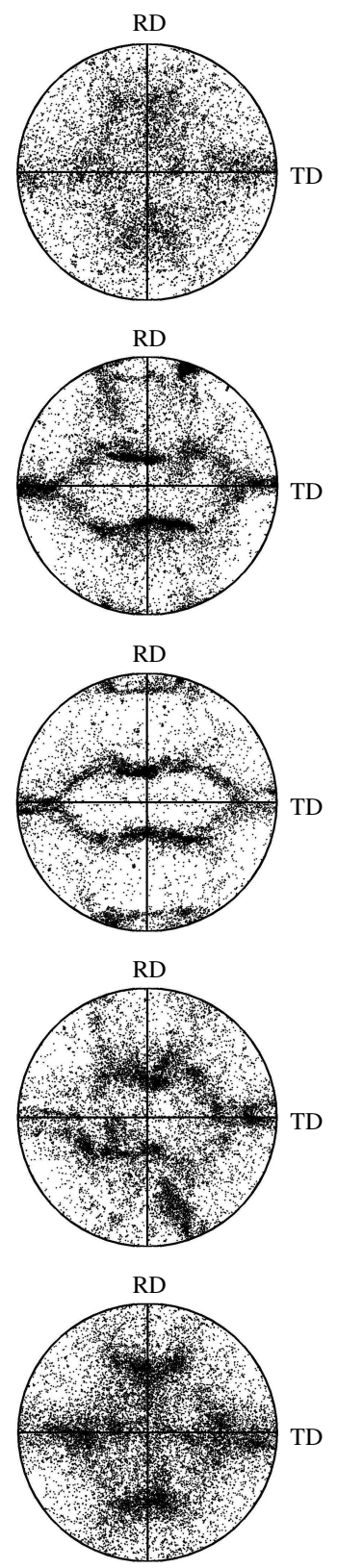

Figure 7: $\langle 111\rangle$ pole figures for as-received AA7055 plate. Starting from the top, the measurements were made on the top surface, $\mathrm{t} / 4, \mathrm{t} / 2,3 \mathrm{t} / 4$ and bottom surfaces. 
inconel platens fitted with 500 Watt cartridge heaters, water-cooled jackets, and type-K thermocouples, controlled by Omega CN2011 controllers.

The samples were upright cylinders, machined from the as-received hot rolled plates with the compression axis aligned with the rolling direction. The cylinders had a recess machined in each end (see Figure 8), which was filled with a 2:1 mixture of vacuum grease and colloidal graphite prior to testing [17]. Compression tests were run on these samples at two different constant crosshead velocities, corresponding to approximate strain rates of $10^{-3} \mathrm{~s}^{-1}$ or $1 \mathrm{~s}^{-1}$.

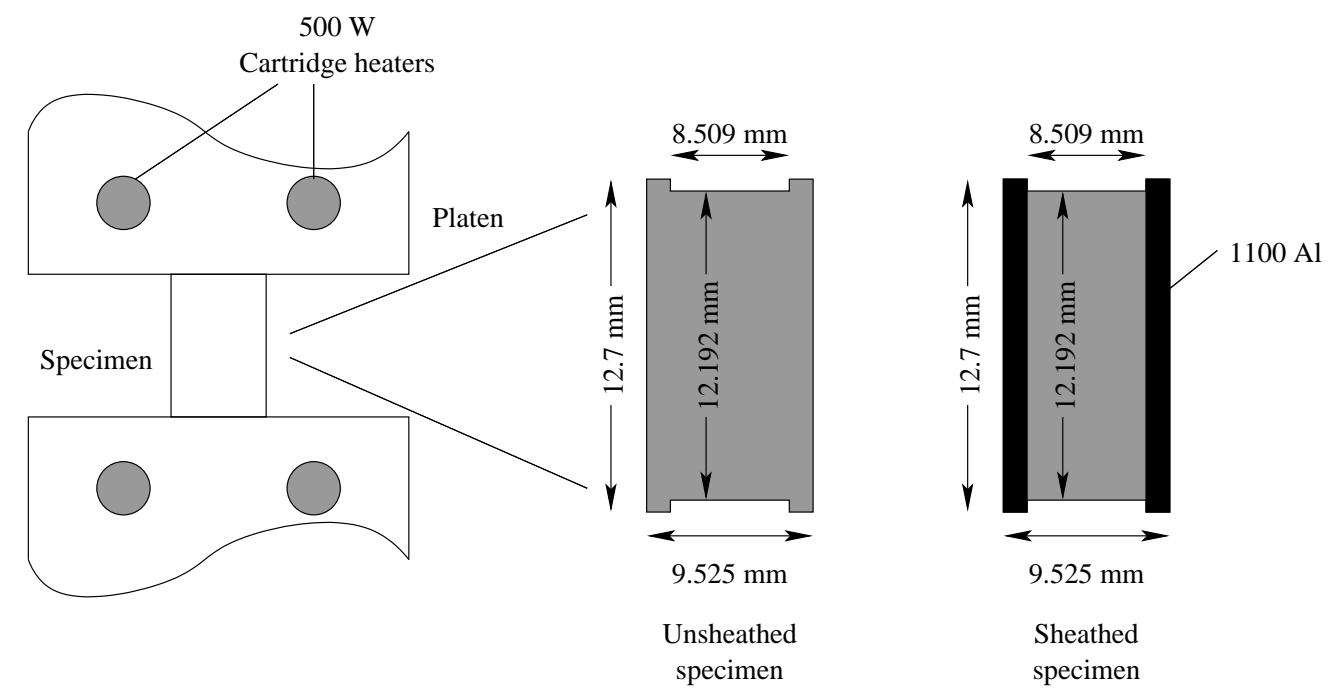

Figure 8: Schematic of test rig and specimen

A second purpose for carrying out these high temperature deformation studies was to assess the evolution of damage, manifested as porosity beginning in grain boundaries, observable by metallographic examination of the deformed specimens. This porosity is thought to be associated with melting of some of the residual secondary phases and extended by deformation. During very high temperature deformation, the material tended to come apart during compression along grain boundaries by coalescence of pores, as shown in Figure 9(a). To preserve specimen integrity under such conditions, a modification of the specimen design was made, whereby the test material was press-fit into a thin-walled sheath of 1100 aluminum. The sheath, due to its thin wall, provides minimal containment on the core specimen, as seen in Figure 9(b). The axial stress in the sheath can be subtracted from the measured total stress to reveal the response of the core.

Following industrial practice, and consistent with our DSC measurements of the dissolution of $\eta$ phases, specimens were homogenized at $480^{\circ} \mathrm{C}$ for one hour. After this treatment, the platen and specimen were brought to the desired test temperature in the range from $380^{\circ} \mathrm{C}$ to $500^{\circ} \mathrm{C}$ over a time of three to five minutes, and then held at that temperature for three minutes prior to compression. The total time near the test temperature (equilibration + hold time) was from five to eight minutes. Immediately following compression, samples were removed from the platens and quenched in cold tap water. 


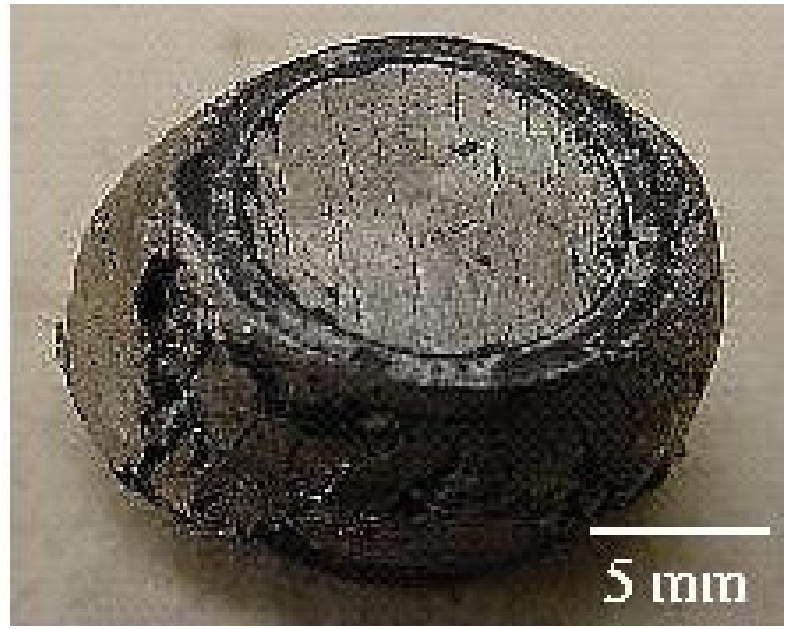

(a) Original specimen design

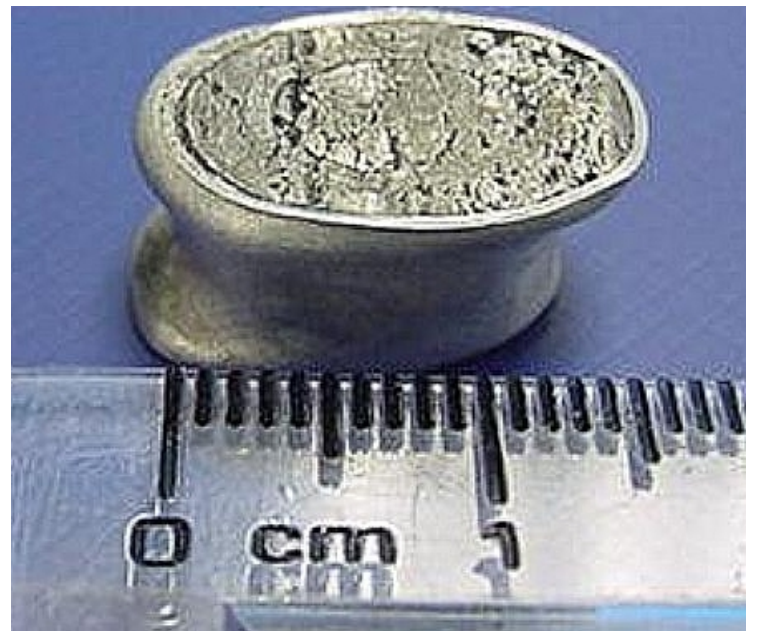

(b) Sheathed specimen design

Figure 9: Compression sample design evolution - addition of 1100 Aluminum sheath provides containment at higher temperatures

Measured true stress-true strain curves from these tests are shown in Figure 10. The strain shown has had the elastic response of the material and the load frame subtracted. No hardening is observed, and after about $2.5 \%$ strain, the material flows at constant saturation stress $\sigma_{\text {sat }}$, which depends on temperature and strain rate. Cerri et al [18] reported similar behavior in hot torsion testing up to $400^{\circ} \mathrm{C}$ of 7012 and 7075 alloys, as did Sheppard and Wright [19] for dilute aluminum alloys at temperatures up to $500^{\circ} \mathrm{C}$.

Our compression data can be correlated by fitting the data to a power law steady state creep model [20]

$$
\frac{\sigma_{s a t}}{\mu(T)}=A_{0}^{1 / n}\left[\dot{\varepsilon} \exp \left(\frac{Q_{D}}{R T}\right)\right]^{1 / n}
$$

where $\mu(T)$ is the shear modulus as a function of temperature $T$ [21], $\dot{\varepsilon}$ is the strain rate, $Q_{D}$ is the activation energy for diffusion, taken to be $120 \mathrm{~kJ} / \mathrm{mol}$ corresponding to the diffusion of $\mathrm{Zn}$ in $\mathrm{Al}$ [22], and $R$ is the ideal gas constant. We refer to the quantity in square brackets in Eq. (1) as $\zeta$, the temperature-compensated strain rate. $A_{0}$ and $n$ are model constants which can be extracted by plotting the experimentally measured $\sigma_{\text {sat }} / \mu$ versus $\zeta$ on logarithmic scales, as shown in Figure 11. Also included in this figure are tensile data for 7050 reported by Ghosh [23], previously unpublished results from hot torsion tests on 7050 from Giardina [24], and data from Sheppard et al. on 7075 [25]. It can be readily seen that the response of all three alloys is quite similar.

The data fall into three regimes. For $\zeta<5$, we find $n=1.2$, and for $5<\zeta<9$, $n=4.47$. The latter region is commonly referred to as "five-power law" creep $[20,26,27]$. When $\zeta>9$, we find $n=10.2$. We will see later that during hot rolling, nearly all of the deformation takes place in this latter regime. One would expect a progression into a "power 


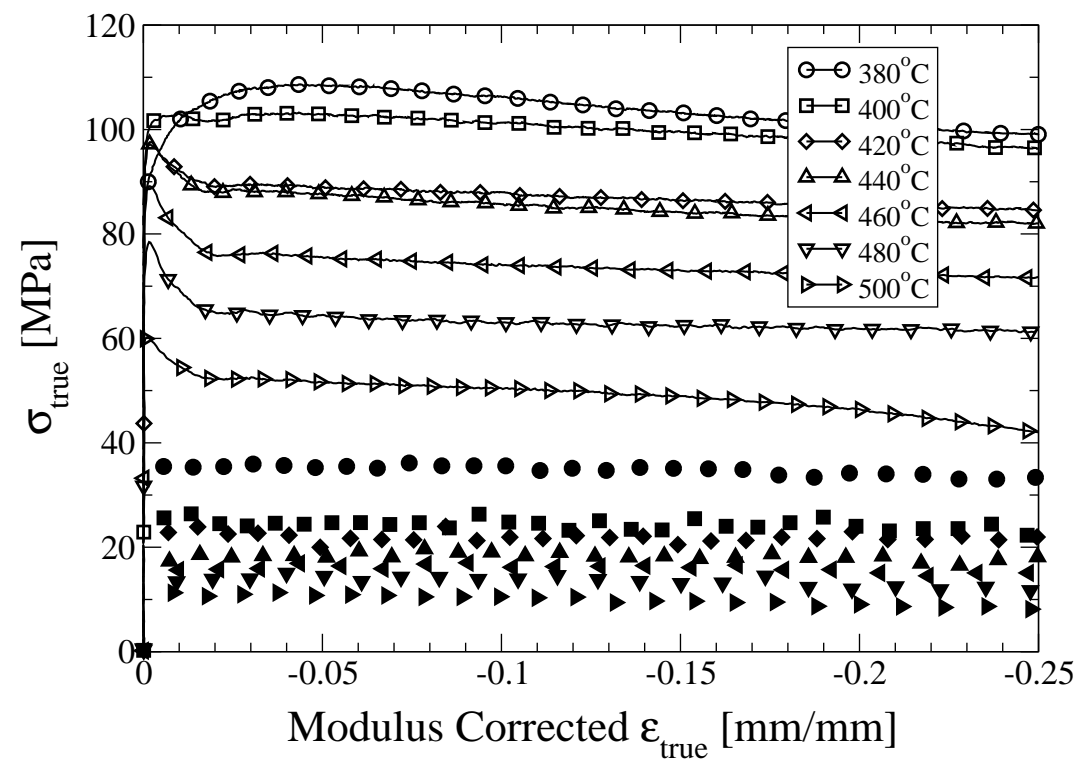

Figure 10: Mechanical behavior of homogenized AA7055. Filled symbols are for tests with $\dot{\varepsilon}=10^{-3} \mathrm{~s}^{-1}$, and open symbols are for tests with $\dot{\varepsilon}=1 \mathrm{~s}^{-1}$. Symbol shape indicates the testing temperature.

law breakdown" regime for the homogenized material as stress is increased through higher strain rate. However, for consistency with crystal plasticity simulations to be described, we will adopt the phenomenological characterization through a power law. Specifically, both simulation of viscoplastic flow in rolling and evolution of texture (as a postprocessing operation) will be conducted using a power law form with identical stress exponent. We also tested a few samples with the compression axis oriented along the normal to the rolling direction. The results from these tests, indicated as "ND" in Figure 11, are indistinguishable from the tests conducted with the specimen axis parallel to the rolling direction. This indicates that although the rolling process itself is constrained by kinematics, the material response is isotropic.

Samples from the tests performed with $\dot{\varepsilon}=1 \mathrm{~s}^{-1}$ at $420,450,455,460,480$ and $500^{\circ} \mathrm{C}$ were prepared for SEM in order to examine the evolution of internal damage. Three orthogonal cuts were made with a diamond saw to expose surfaces whose normal was in the rolling direction (RD), perpendicular to the rolling plane (ND), and in the transverse plane (TD). The surfaces were polished, etched, and imaged using a procedure similar to that described for the specimens used in texture measurements.

SEM images from deformed specimens, shown in Figures 12, indicate that localized damage begins to appear in specimens deformed at $455^{\circ} \mathrm{C}$ and above, as dark spots at grain boundaries. At $480^{\circ} \mathrm{C}$, Figure $12(\mathrm{e})$, similar dark spots show distinct linear arrangements. In Figure $12(\mathrm{f})$, from compression at $500^{\circ} \mathrm{C}$, there is a rippled edge to each microcrack, as if multiple voids had coalesced to form the elongated crack. The voids appear aligned in distinct patterns and show both increased frequency and severity with increasing temperature 


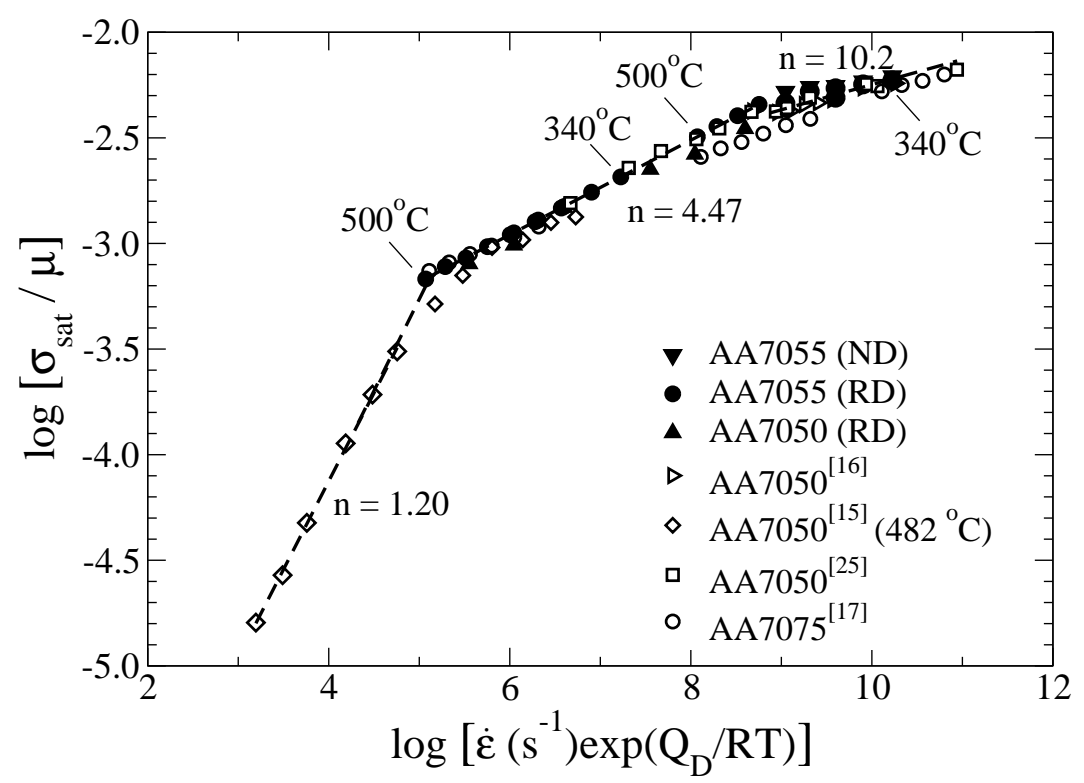

Figure 11: Saturation stress, normalized by shear modulus, versus temperature compensated strain rate for compression tests in this work (solid symbols), torsion tests by Giardina [24], tension tests by Ghosh [23], compression tests by Hander [28], and results for 7075 from a correlation by Sheppard et al [25].

of deformation. Note also that the micrographs from all of these samples clearly show that the original elongated grains remain, and that there has been no recrystallization during heat treatment or deformation.

In the next section, the measured constitutive relation is implemented in a numerical model for hot rolling. The fact that the material can be characterized by the saturation stress at any particular temperature and strain rate permits modeling the material as a nonNewtonian fluid. The tests presented in this section also clearly show that damage begins to occur in the material when it is deformed at temperatures above about $455^{\circ} \mathrm{C}$. We will therefore look for rolling conditions that lead to this undesirable state.

\subsection{Rolling model}

To model the hot rolling process, we follow a two step procedure. We first compute the velocity, temperature and pressure fields using a material model which derives from the mechanical property measurements. A subsequent post-processing step is executed to derive through-thickness texture evolution from the computed velocity field. We emphasize that the kinematic constraints imposed by the boundary value problem for rolling and the relatively rate-sensitive, non-hardening material response allow for this sequential treatment of the thermomechanical problem and texture evolution. This is a relaxation of the more rigorous, fully-coupled approach advanced by Mathur and Dawson [29] for analysis of cold rolling a rate-insensitive work hardening material. As a practical consequence, the (much) reduced 


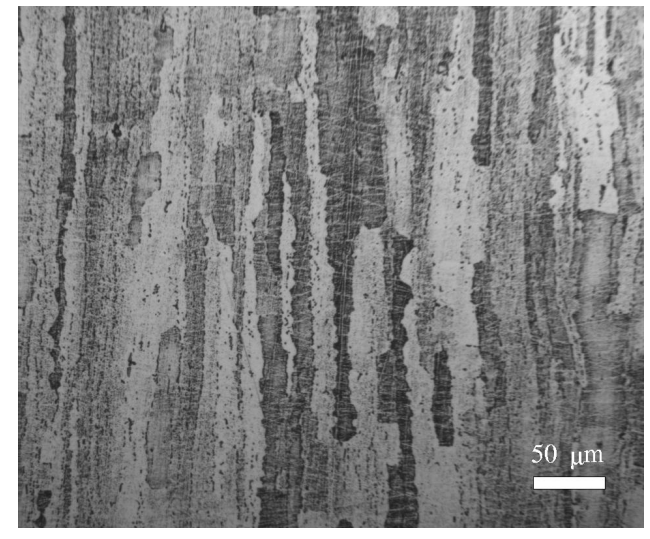

(a) $420^{\circ} \mathrm{C}$

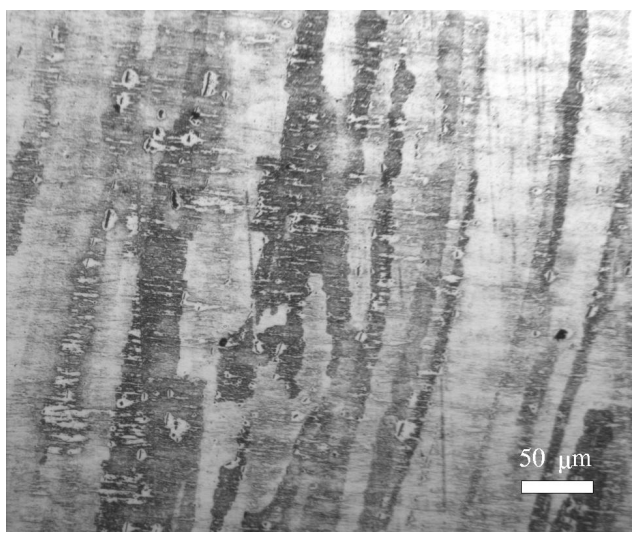

(c) $455^{\circ} \mathrm{C}$

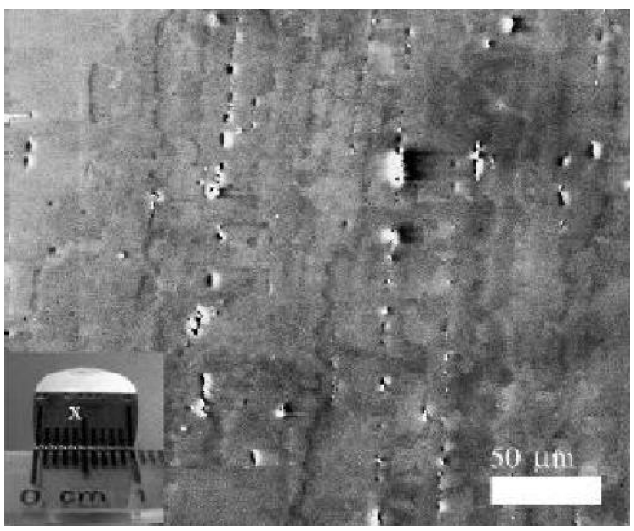

(e) $480^{\circ} \mathrm{C}$

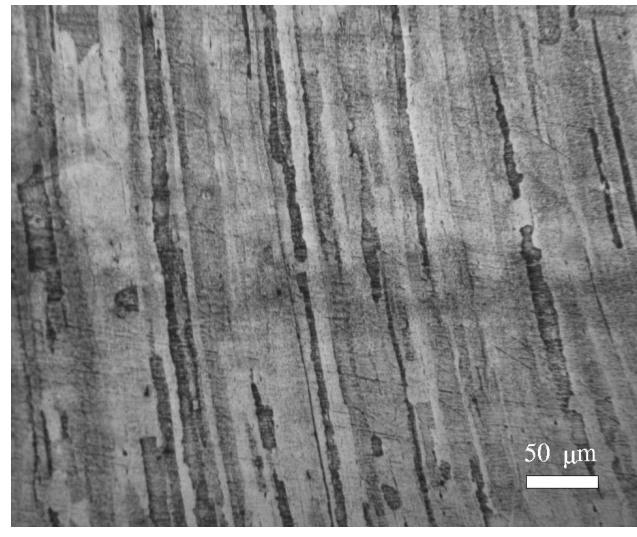

(b) $450^{\circ} \mathrm{C}$

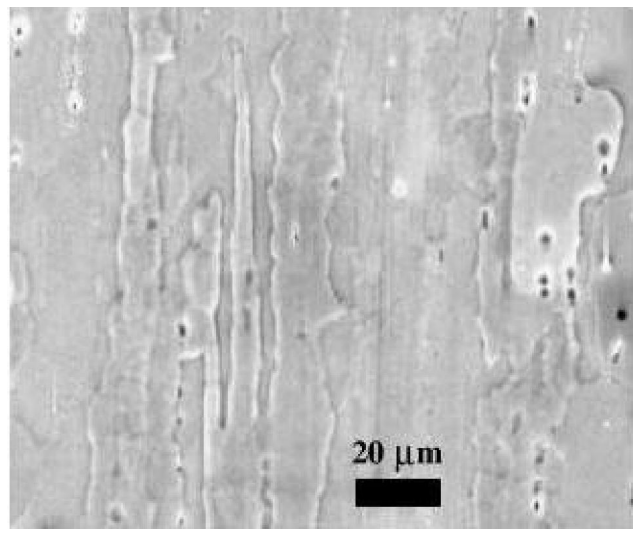

(d) $460^{\circ} \mathrm{C}$

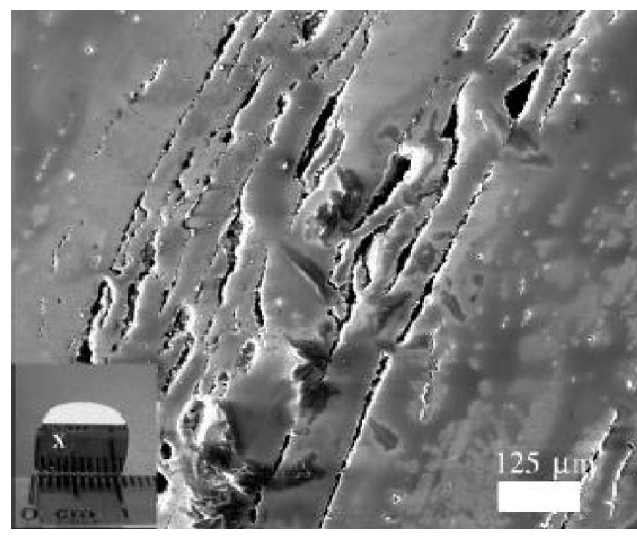

(f) $500^{\circ} \mathrm{C}$

Figure 12: Microstructures from homogenized 705X compressed at various temperatures at a strain rate of $1 \mathrm{~s}^{-1}$ 
computational overhead in the decoupled approach allows for timely study of multi-pass rolling, as well as parametric studies of friction and heat transfer to be detailed below.

The compression tests show that, in the temperature range of interest for hot rolling, the material flows at constant stress $\sigma_{\text {sat }}$ once the strain exceeds $2.5 \%$. Since the strains experienced in hot rolling are considerably higher than this value, the material can be modeled as an incompressible viscous fluid, with viscosity a function of strain rate and temperature derived from the constitutive relation in Eq. (1). Considering the material to be a non-Newtonian fluid permits the use of a commercial computational fluid dynamics package FiDAP ${ }^{T M}$ to model the hot rolling process.

The material is modeled as an incompressible, purely viscous, non-Newtonian fluid obeying the constitutive relation

$$
\boldsymbol{\tau}=2 \Lambda(\dot{\varepsilon}, T) \mathbf{D}
$$

Here $\Lambda$ is the non-Newtonian viscosity, $\boldsymbol{\tau}$ and $\mathbf{D}$ are the deviatoric stress and rate of deformation tensors, respectively, and the effective strain rate $\dot{\varepsilon}$ is defined as

$$
\dot{\varepsilon}=\sqrt{(2 / 3) \mathbf{D}: \mathbf{D}}
$$

By contracting $\boldsymbol{\tau}$ with itself, a scalar form for Eq. (2) can be found

$$
\tau=3 \Lambda(\dot{\varepsilon}, T) \dot{\varepsilon}
$$

where $\tau=\sqrt{(3 / 2) \tau: \tau}$ is the scalar magnitude of $\boldsymbol{\tau}$. This form permits the behavior of the material in a $3 \mathrm{D}$ stress state to be determined form the uniaxial compression response, with the non-Newtonian viscosity $\Lambda$ given by

$$
\Lambda=\frac{\sigma_{s a t}(\dot{\varepsilon}, T)}{3 \dot{\varepsilon}}
$$

where $\sigma_{\text {sat }}(\dot{\varepsilon}, T)$ may be computed from the constitutive relation in Eq. (1).

The viscosity model is implemented as a user subroutine in FiDAP ${ }^{T M}$. Within each element, $\mathbf{D}$ is computed at each integration point using the putative velocity solution, from which $\dot{\varepsilon}$ is computed using Eq. (3). The combination of $\dot{\varepsilon}$ and $T$ yields the local saturation stress from Eq. (1), and substitution of this value of $\sigma_{\text {sat }}$ into Eq. (5) gives the local viscosity. Note that as the strain rate approaches zero, the viscosity computed from Eq. (5) is unbounded. Using a maximum cutoff viscosity of $100 \mathrm{MPa} \cdot \mathrm{s}$ gave good numerical stability, and the simulation results were unaffected by small changes in this limiting value. The velocity solution is then found using these viscosity values, and the procedure is iterated to convergence.

The final four reversing passes were simulated, assuming 2-D, steady-state conditions. In these four passes, plate thickness is reduced from $127 \mathrm{~mm}$ to $25.4 \mathrm{~mm}$ with a constant 25.4 $\mathrm{mm}$ draft in each pass. A representative finite element mesh, corresponding to the second pass, is shown in Figure 13. Geometrically similar meshes were used in the deformation zone for each pass, with dimensions reduced accordingly. Sufficient entry and exit lengths were included such that the computed results were independent of the cutoff points. The rolls are 
not included in the simulations, but are represented by their respective tangential velocities in the roll bite. Additional boundary conditions are also indicated in Figure 13. Note that symmetry is not imposed at the midplane, and that, based on experimental observations, the various coefficients are specified independently on the top and bottom surfaces.

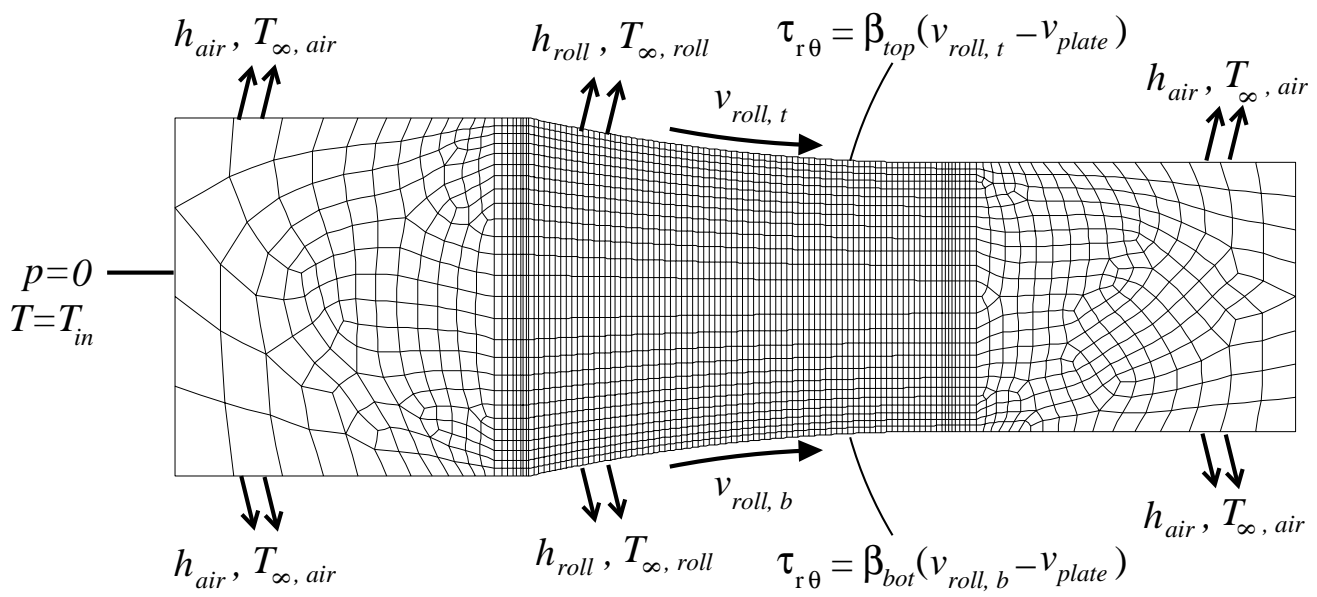

Figure 13: Finite element mesh for pass 2, in which thickness is reduced from $101.6 \mathrm{~mm}$ to $76.2 \mathrm{~mm}$. General boundary conditions are shown specified independently on top and bottom surfaces

Following Mathur and Dawson [30], friction at the roll/plate interface is modeled using a slip model, where the shear stress is assumed to be proportional to the difference between the roll surface speed $v_{\text {roll }}$ and the local tangential surface speed of the plate $v_{\text {plate }}$, viz.

$$
\tau_{r \theta}=\beta\left(v_{\text {roll }}-v_{\text {plate }}\right)
$$

The slip coefficient $\beta$ is a simulation parameter, representing lubrication conditions, that controls the relative slip between the roll and plate. Higher values of $\beta$ correspond to less slip, and higher shear stresses along the arc of contact. The model accommodates different values for $\beta$ on the top and bottom surfaces.

Heat transfer on the external surfaces is modeled by means of a convection boundary condition. Industrial plant measurements suggest a heat transfer coefficient, $h_{\text {air }}$, of 0.85 $\mathrm{kW} / \mathrm{m}^{2} \mathrm{~K}$ for coolant-covered surfaces of the plate exposed to air, corresponding to the region outside the roll bite [31]. Heat transfer coefficients between the plate and roll, $h_{\text {roll }}$, have been reported to range from as low as $9.3 \mathrm{~kW} / \mathrm{m}^{2} \mathrm{~K}$ for cold-rolling of commercially pure aluminum [32] to as high as $450 \mathrm{~kW} / \mathrm{m}^{2} \mathrm{~K}$ for hot-rolling of AA5000 series alloys [33]. The computed texture was relatively insensitive to the value of $h_{\text {roll }}$ when it was in the range $10 \mathrm{~kW} / \mathrm{m}^{2} \mathrm{~K}$ to $60 \mathrm{~kW} / \mathrm{m}^{2} \mathrm{~K}$. For the simulations described in detail below, we used $h_{\text {roll }}=21$ $\mathrm{kW} / \mathrm{m}^{2} \mathrm{~K}$, a figure suggested by plant measurements [31].

For each pass, the inlet temperature was set to the lay-on temperature of $427^{\circ} \mathrm{C}$. Setting the inlet temperature to be the same for each pass assumes that convective heat losses 
balance viscous dissipation in each pass, a common industrial practice. This condition was verified post-simulation by computing the average exit temperature of the plate cross-section, which was found to deviate by at most $+10^{\circ} \mathrm{C}(+1.5 \%)$ from the lay-on temperature in the simulations.

Grid converged solutions were found using a relatively fine mesh in the deformation zone, containing 1950 elements graded towards the roll boundaries. The fine mesh also extends eight elements outside the roll bite in each direction. The remaining mesh outside the roll bite is coarser, containing a total ranging from 916 to 1047 elements for the four passes depending on inlet and outlet thickness. Interior elements are 9-noded isoparametric quadrilaterals with quadratic velocity and continuous linear pressure interpolation. The boundaries consist of 3-noded quadratically interpolated isoparametric elements. Pressure is set to zero at the inlet. On average, 23 iterations were required to achieve convergence of the solution, using successive substitution to resolve the nonlinearities. Convergence was declared when the rms value of the residual and the relative change in solution vectors normalized by their respective initial values were each less than $10^{-4}$.

An extensive set of simulations was performed to explore the role of the various process parameters. Detailed results are presented for one parameter set, given in Table 1, which produced simulated textures most closely matching those measured experimentally, shown in Figure 7. The sensitivity of the results to the input parameters is discussed as variations from this case. Of particular note, the slip coefficients on the top and bottom are 250 $\mathrm{MPa} / \mathrm{m} / \mathrm{s}$ and $350 \mathrm{MPa} / \mathrm{m} / \mathrm{s}$, respectively, corresponding to larger shear forces at the bottom as suggested by experimental textures. All other parameters are the same at the upper and lower surfaces of the plate.

Table 1: Process parameters for simulation results presented

\begin{tabular}{|r|c|c|}
\hline Parameter & Symbol & Value \\
\hline Bottom slip coefficient & $\beta_{\text {bot }}$ & $350 \mathrm{MPa} / \mathrm{m} / \mathrm{s}$ \\
Top slip coefficient & $\beta_{\text {top }}$ & $250 \mathrm{MPa} / \mathrm{m} / \mathrm{s}$ \\
Tangential roll velocity & $v_{\text {roll }}$ & $1.17 \mathrm{~m} / \mathrm{s}$ \\
Heat transfer coefficient between roll and plate & $h_{\text {roll }}$ & $21 \mathrm{~kW} / \mathrm{m}^{2} \mathrm{~K}$ \\
Reference temperature for roll & $T_{\infty, \text { roll }}$ & $94^{\circ} \mathrm{C}$ \\
Heat transfer coefficient between air and plate & $h_{\text {air }}$ & $0.85 \mathrm{~kW} / \mathrm{m}^{2} \mathrm{~K}$ \\
Reference temperature for air & $T_{\infty, \text { air }}$ & $25^{\circ} \mathrm{C}$ \\
Lay-on temperature & $T_{\text {in }}$ & $427^{\circ} \mathrm{C}$ \\
\hline
\end{tabular}

Figure 14 depicts the computed shear rates for all four passes modeled. The effect of the differential slip coefficients is manifested as an asymmetry in the shear rate distribution, with more shear along the bottom of the plate, where $\beta$ is larger. The deformation is also shown to be non-homogeneous, localizing along lines of maximum shear at about $45^{\circ}$ to RD. This localization is to be expected, because our constitutive relation (Eq. (1)) resembles a shear-thinning power-law fluid with power law exponent $1 / n<1$. As the aspect ratio of the 
deformation zone increases, the number of localized lines increases along with the average strain rate.

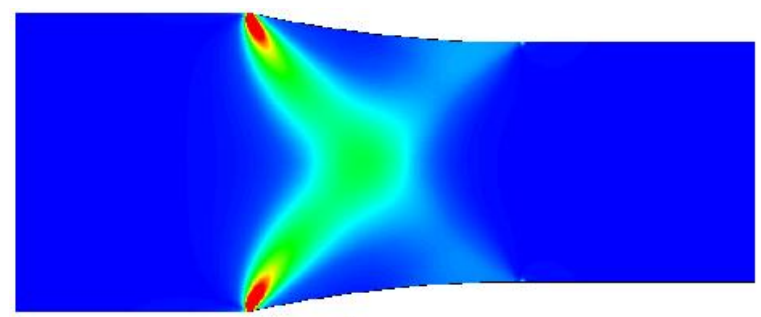

(a) Pass 1

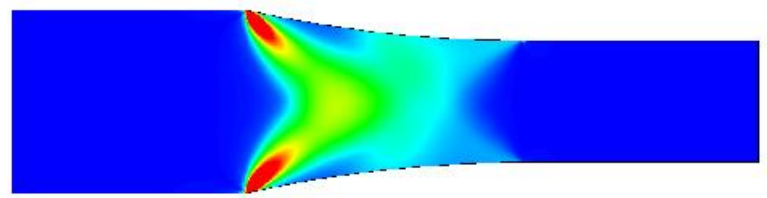

(c) Pass 3

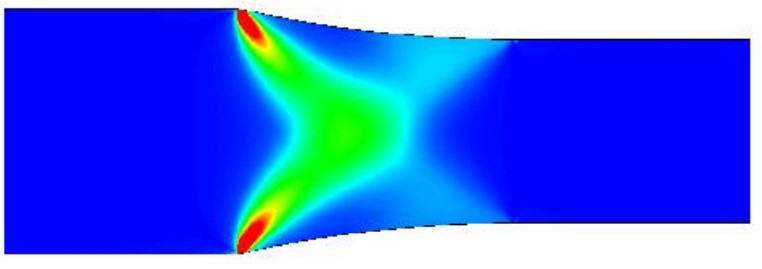

(b) Pass 2

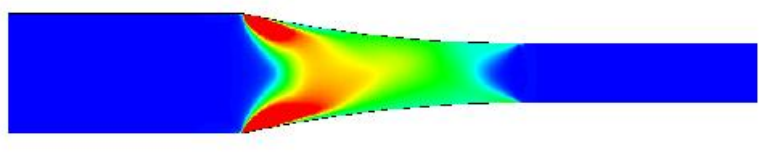

(d) Pass 4

\section{$\begin{array}{llllllll}2.7 & 5.3 & 8.0 & 10.7 & 13.3 & 16.0 & 18.7 & 21.3\end{array}$}

Figure 14: Computed shear rate $\left(\mathrm{s}^{-1}\right)$ computed for each pass. Note the top-to-bottom asymmetry, especially in Pass 4.

Figure 15 shows the shear stress in the plate at the roll/plate interface. Note that the slip model we have chosen ensures that the effective stress in the material does not exceed the saturation stress, without the need for capping. The neutral point is indicated in the figure for reference.

Computed pressure contours are shown in Figure 16. The majority of the material is under hydrostatic compression $(p>0)$. However, negative pressures, or regions of hydrostatic tension, are found at the entrance and exit of the roll bite. Note that these negative pressures are due to local accelerations, and do not derive from elastic unloading, as the material model is purely viscoplastic. Regions of hydrostatic tension are of particular interest because any defects present in the material tend to grow under such conditions. At least some of the negative pressure is an artifact of the slip model inaccurately representing the deformation at these locations.

The temperatures in each pass show similar characteristics. However, the maximum temperature increases with increasing reduction ratio due to greater viscous work. The computed temperature field for Pass 4 (the final pass) is shown in Figure 17. The majority of the material at any given vertical cross-section is nearly isothermal. A thin, cooler layer exists near the surface in the roll bite, where the gradient is high due to the large heat transfer coefficient. The maximum temperature is about $462^{\circ} \mathrm{C}$, which corresponds to the temperature at which damage began to appear in the compression samples. The average temperature at the roll exit for passes $1-4$ was $434,435,439$ and $450^{\circ} \mathrm{C}$, respectively. These results indicate that using the same lay-on temperature for each pass is reasonable. The 


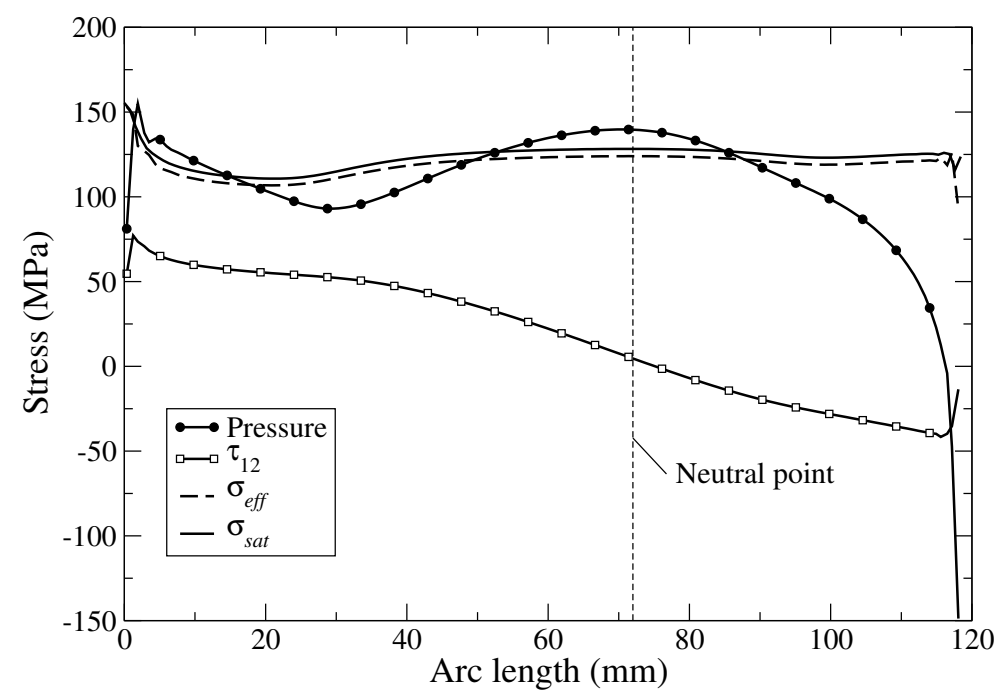

(a) Top roll surface

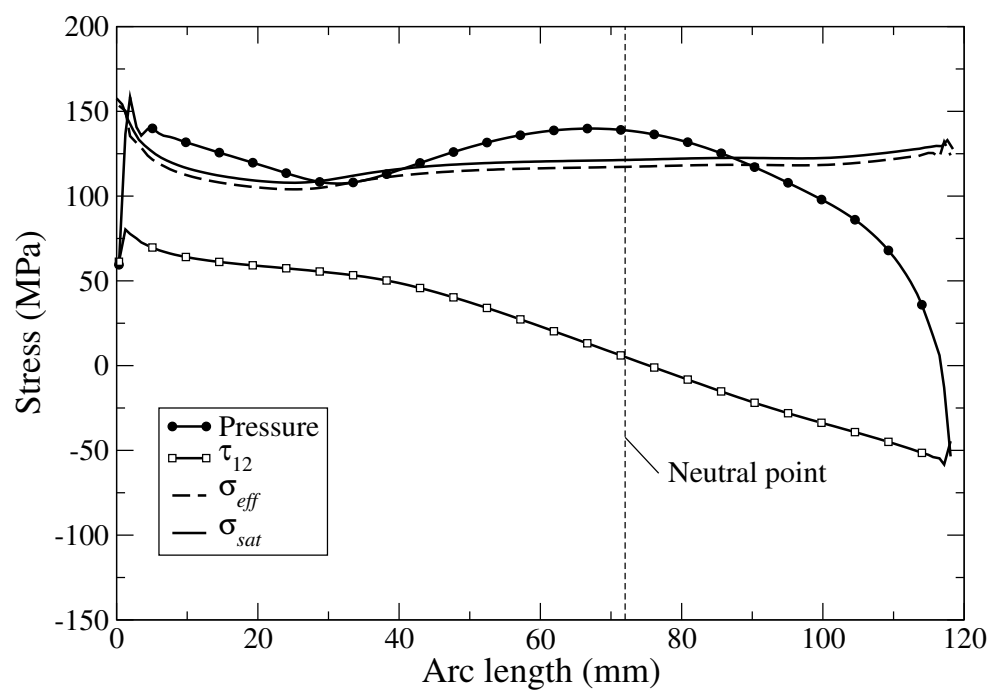

(b) Bottom roll surface

Figure 15: Computed shear stress, saturation stress and pressure along the arc of contact for the upper and lower rolls in Pass 4. The total normal stress is also shown. 


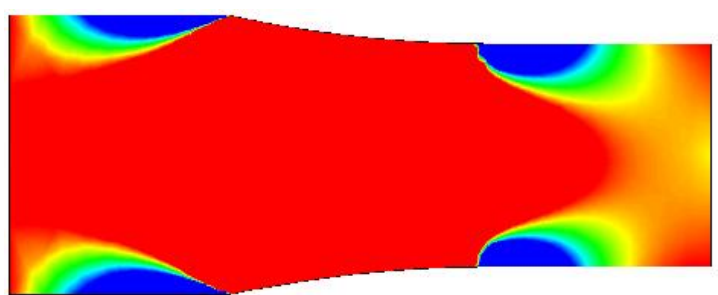

(a) Pass 1

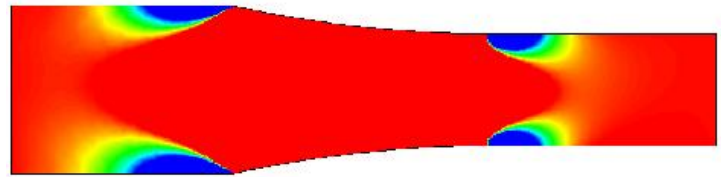

(c) Pass 3

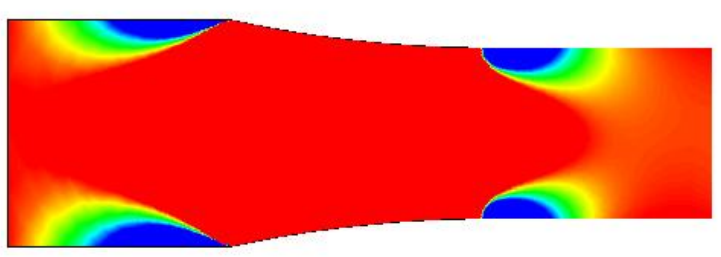

(b) Pass 2

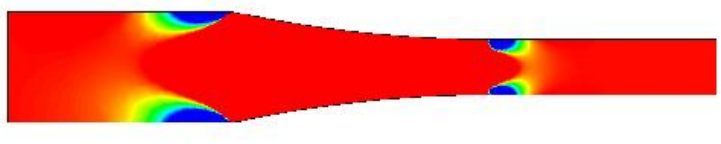

(d) Pass 4

$-8.8-7.7-6.6-5.5-4.4-3.3-2.2-1.1$

Figure 16: Computed pressure distribution (MPa) for each pass.

temperature distribution within the plate is discussed further below, when the sensitivity of the model results to the value of heat transfer coefficient is examined.

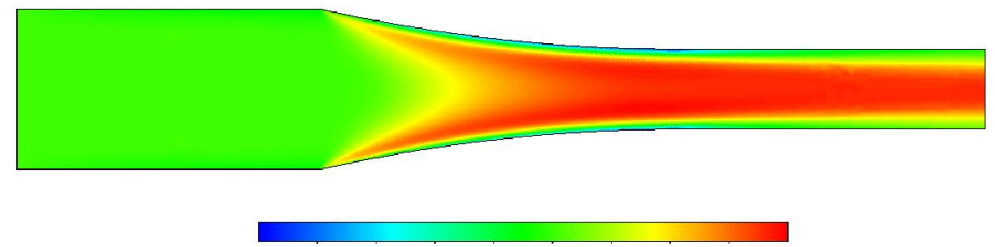

387397407416426436446455

Figure 17: Computed Pass 4 temperature distribution $\left({ }^{\circ} \mathrm{C}\right)$ with a lay-on temperature of $427^{\circ} \mathrm{C}$

With the velocity field in hand, texture evolution through the rolling process can be computed using a viscoplastic self-consistent (VPSC) polycrystal plasticity code [34, 35]. Within VPSC, each grain in the polycrystal is treated as an inclusion in a homogeneous effective medium whose properties are determined from the bulk average. The response of each grain obeys a power law constitutive form, where the rate sensitivity is specified as 10.2, consistent with our experimental measurements. At each time step, texture is updated based on the imposed deformation, slip system shear strengths, and current texture. To determine the imposed deformation, a set of 500 randomly oriented massless particles is introduced at the inlet, and their motion is integrated through time using the computed velocity field. These data provide the velocity gradients necessary to evolve the texture along streamlines. Texture is evolved continuously through the final four passes, i.e. the texture computed after Pass 1 is used as the initial texture for Pass 2 and so on. While simulations of rolling passes 
were performed with the "left-to-right" flow of material, as indicated in Figures 14-16, the resulting velocity gradients were modified (through sign change of off-diagonal components) to simulate texture evolution in reversing passes.

Figure 18(b) shows simulated $\langle 111\rangle$ pole figures after Pass 4 for the process parameters outlined in Table 1. Simulated textures match quite well to experimental measurements, reproduced from Figure 7 in Figure 18(a) for comparison. At the bottom surface a strong shear texture is predicted. The simulated top surface texture matches closely to experimental measurements, with a slightly greater rotation about TD in the simulations. Simulated textures at the quarter and half-planes also very closely resemble experimental measurements. At the midplane, a plane strain compression texture is observed, as expected for rolling processes. Note that whereas in cold rolling friction between the plate and rolls can be measured indirectly through roll torque, this does not work well in hot rolling, where the frictional forces represent a much smaller fraction of the total torque in the mill. Thus, it is essential to use indirect means, such as the texture, as an indication of the thermomechanical history of the plate.

Some of the model parameters, such as roll diameter, roll speed and lay-on temperature were chosen to model a desired pass schedule. In contrast, the slip coefficients and heat transfer coefficients are very difficult to measure experimentally; a parametric study was performed to determine the sensitivity of the computed results to variations in these parameters.

The simulated texture is very sensitive to the values of the slip coefficients. To illustrate this point, the results of simulations using symmetric values for $\beta$ of 150 and $300 \mathrm{MPa} / \mathrm{m} / \mathrm{s}$, respectively, are shown in Figure 19(a) and (b). For these two cases, the heat transfer coefficients were the same as in the simulations reported above, where $h_{\text {roll }}=21 \mathrm{~kW} / \mathrm{m}^{2} \mathrm{~K}$. When the smaller value of $\beta$ is used, a plane-strain compression texture extends through the majority of the plate. Additionally the $45^{\circ} \mathrm{ND}$ rotated cube shear texture is absent at the surface, which is inconsistent with the experimental measurements reported earlier. Using a higher value of $\beta$ produces the $45^{\circ}$ ND rotated cube shear texture at the surface.

Note that the adjustment of the frictional conditions through assessment of texture offers a useful alternative to tuning them through comparison to roll force or torque. In hot rolling of aluminum, roll force and torque are dominated by reduction, whereas the contribution due to lubrication conditions is difficult to assess - with a complex (and offsetting) interplay between heat transfer, viscous heating and lubrication. [36] From the practical standpoint, friction and heat transfer coefficients are difficult to measure in the production environment. Validating a model through comparison to roll torque integrates model details into a single parameter; the relative contribution of underlying factors, such as changes in lubricant behavior, metal constitutive response and heat transfer with speed for example, is obfuscated. In contrast, comparison of predicted and measured texture reveals the degree to which one captures gradients in the boundary value problem that serves as an idealization of the rolling operation. Faithful reproduction of such gradients supports the notion that boundary conditions and non-linear material response are well-represented in the model.

Forward slip also provides a secondary check as to whether the model results are reason- 

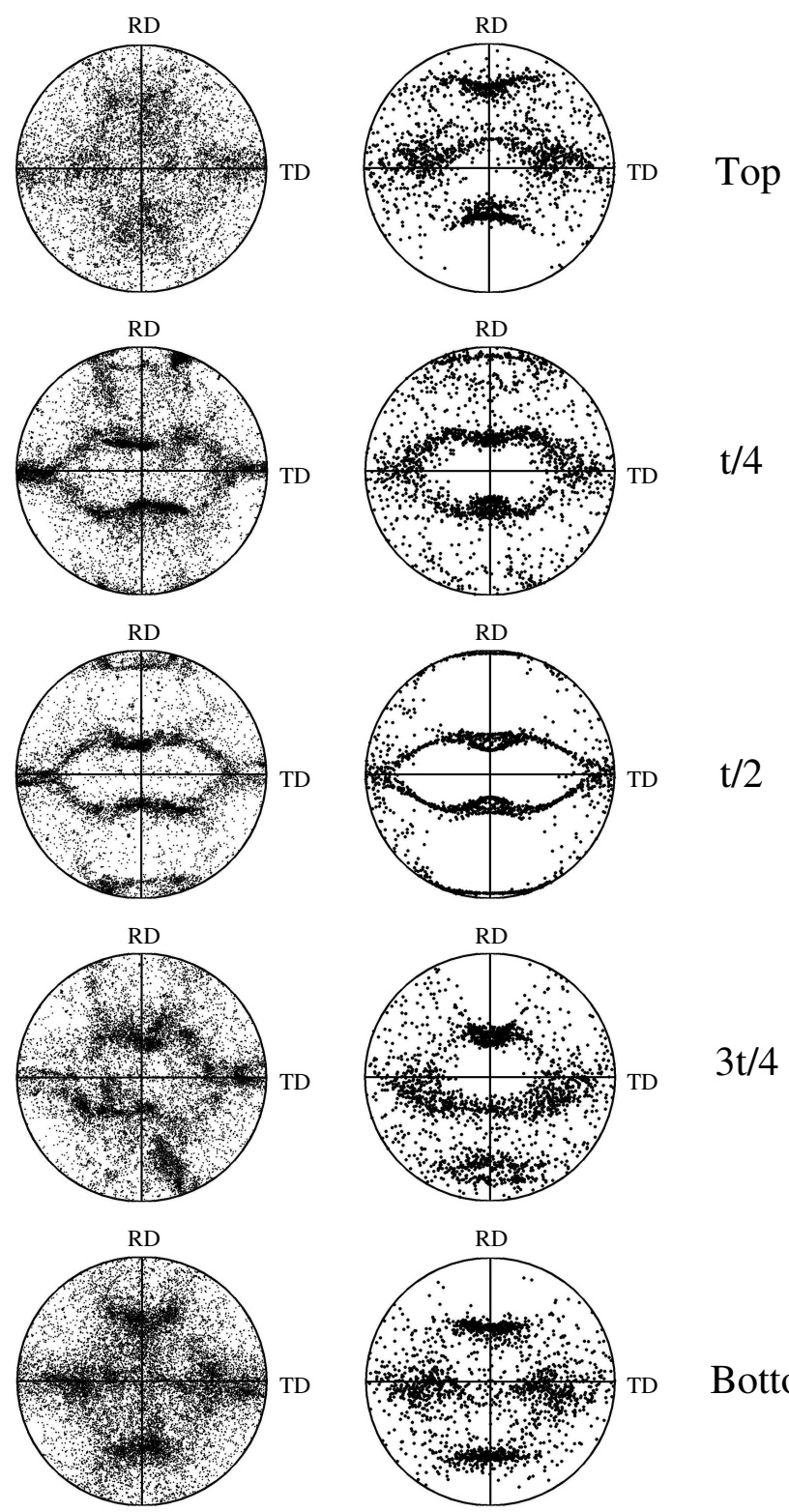

(a)

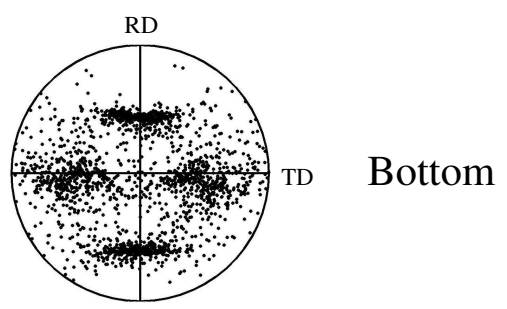

(b)

Figure 18: $\langle 111\rangle$ pole figures (a) experimental (b) Simulated texture for model parameters listed in Table 1 

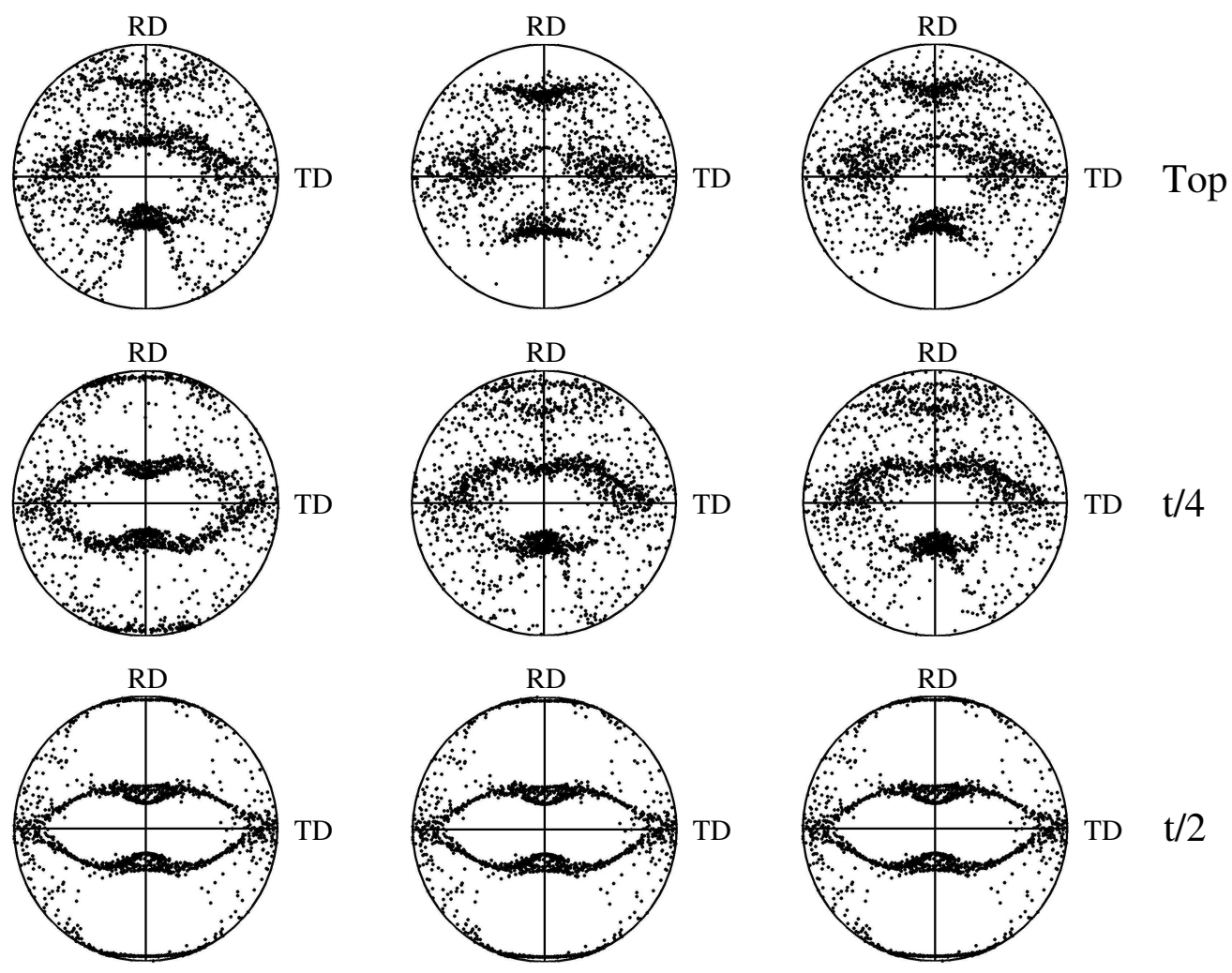

(a)

(b)

(c)

Figure 19: Simulated $\langle 111\rangle$ pole figures for (a) $\beta=150 \mathrm{MPa} / \mathrm{m} / \mathrm{s}, h_{\text {roll }}=21 \mathrm{~kW} / \mathrm{m}^{2} \mathrm{~K}$, (b) $\beta$ $=300 \mathrm{MPa} / \mathrm{m} / \mathrm{s}, h_{\text {roll }}=21 \mathrm{~kW} / \mathrm{m}^{2} \mathrm{~K}$, and (c) $\beta=300 \mathrm{MPa} / \mathrm{m} / \mathrm{s}, h_{\text {roll }}=60 \mathrm{~kW} / \mathrm{m}^{2} \mathrm{~K}$ 
able. We find that in the four passes model, corresponding to reductions of $20 \%, 25 \%, 33.3 \%$ and $50 \%$, the computed forward slip for the base case are $3.4 \%, 5.1 \%, 7.7 \%$ and $14.5 \%$, respectively. These predictions are consistent with experimental measurement of forward slip reported in the literature for the hot rolling of pure aluminum strip. [36,37]

Simulated textures proved to be relatively insensitive to variations in the $h_{\text {roll }}$ in the range of $10-60 \mathrm{~kW} / \mathrm{m}^{2} \mathrm{~K}$. This is illustrated in Figure $19(\mathrm{c})$, which shows almost no change in simulated texture for the case $h_{\text {roll }}=60 \mathrm{~kW} / \mathrm{m}^{2} \mathrm{~K}$ and $\beta=300 \mathrm{MPa} / \mathrm{m} / \mathrm{s}$. Figure 20 shows the plate exit temperature across the thickness after Pass 4 for different values of $h_{\text {roll }}$. Although the maximum temperature is essentially unaffected by $h_{\text {roll }}$, the location of the maximum temperature shifts toward the midplane with increasing $h_{\text {roll }}$. Also note that asymmetric specification of $\beta$ results in a slightly higher maximum temperature in the bottom half of the plate. The effects of viscous heating are evident as the maximum temperature exceeds $460^{\circ} \mathrm{C}$, at which the onset of damage is suggested in our compression tests. Note also that the position of the maximum temperature point moves toward the center of the plate as $h$ increases. This may afford the material further protection from failure.

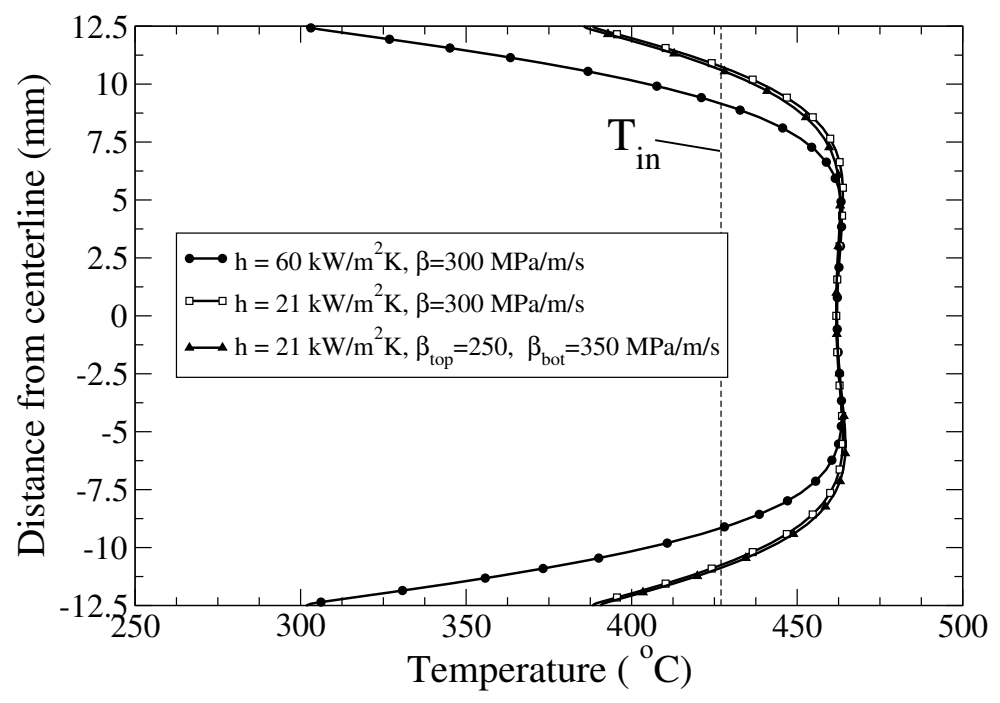

Figure 20: Pass 4 exit temperature profile

Examination of simulation results provide an a posteriori consistency check of the model. The accumulated strain exceeds $2.5 \%$ everywhere in the plate almost immediately upon entering the deformation zone. This makes it reasonable to model the material using the purely viscoplastic model derived from experimental saturation stress data. The temperature compensated strain rate $\zeta$ can be computed from the final solution. These data show that virtually the entire deformation zone falls within the range where $1 / n=10.2$, consistent with the value used in VPSC to compute the texture evolution. A small portion of the material, near the entrance to the roll bite, has values of the temperature compensated strain rate outside the range of our experimental measurements. The constitutive model was extrapolated for these locations. 


\subsubsection{Damage modeling}

Our ultimate goal in this work is to quantitatively define the thermomechanical processing window. We propose a damage parameter that incorporates our experimental observation that damage first appears when deformation is carried out above $455^{\circ} \mathrm{C}$, and increases with increasing temperature; and that the probably deformation mechanism is shearing along grain boundaries. To that end, we define

$$
\chi=\oint_{S} \tau_{\max } \mathcal{A}(T) d S
$$

where $S$ is a streamline, $\tau_{\max }$ is the magnitude of the maximum shear stress at any point along the streamline, and $\mathcal{A}(T)$ is given by

$$
\mathcal{A}(T)= \begin{cases}0 & T \leq 455 \\ T-455 & T>455\end{cases}
$$

This parameter is readily computed from the data already extracted to compute the texture.

Figure 21 shows the computed damage field for the final pass with $v_{\text {roll }}=1.17 \mathrm{~m} / \mathrm{s}$. Note that for this roll speed, the final pass was the only pass in which the temperature exceeded $455^{\circ} \mathrm{C}$ anywhere in the plate. Figure 22 shows the accumulated damage at the exit of the deformation zone for various roll speeds. Note that damage, as measured by this criterion, is found even at relatively low roll speeds. The maximum value of $\chi$ increases with roll speed, and its location shifts from t $/ 4$ for $v_{\text {roll }}=0.94 \mathrm{~m} / \mathrm{s}$ to nearly t $/ 10$ for $v_{\text {roll }}=1.5$ $\mathrm{m} / \mathrm{s}$. In order to eliminate the possibility of damage during hot rolling, process parameters must be chosen such that temperatures do not reach $455^{\circ} \mathrm{C}$. For the case studied here, that corresponds to running at $v_{\text {roll }}<0.4 \mathrm{~m} / \mathrm{s}$. Alternatively, smaller reductions may be taken in final passes. Further experimental work is required to determine a threshold value of $\chi$, in order to make full use of the model in defining the TPW and optimizing the hot rolling process.

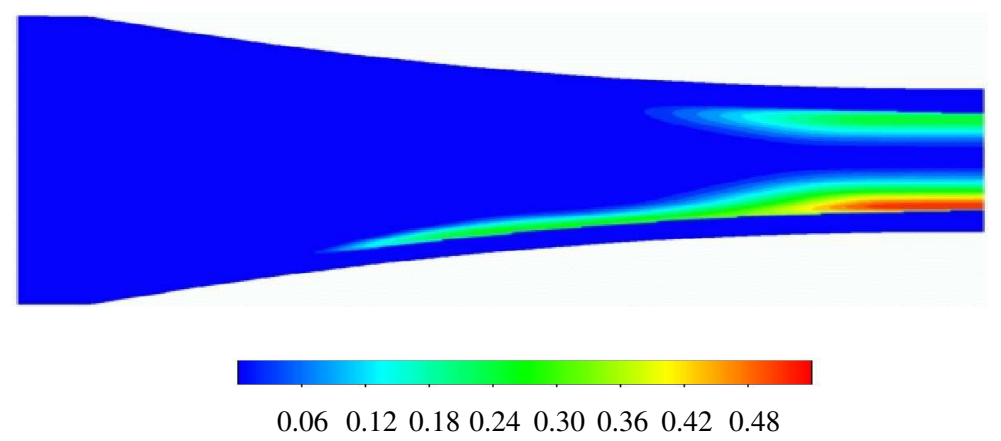

Figure 21: $\chi$ damage field for pass four with $v_{\text {roll }}=1.17 \mathrm{~m} / \mathrm{s}$ 


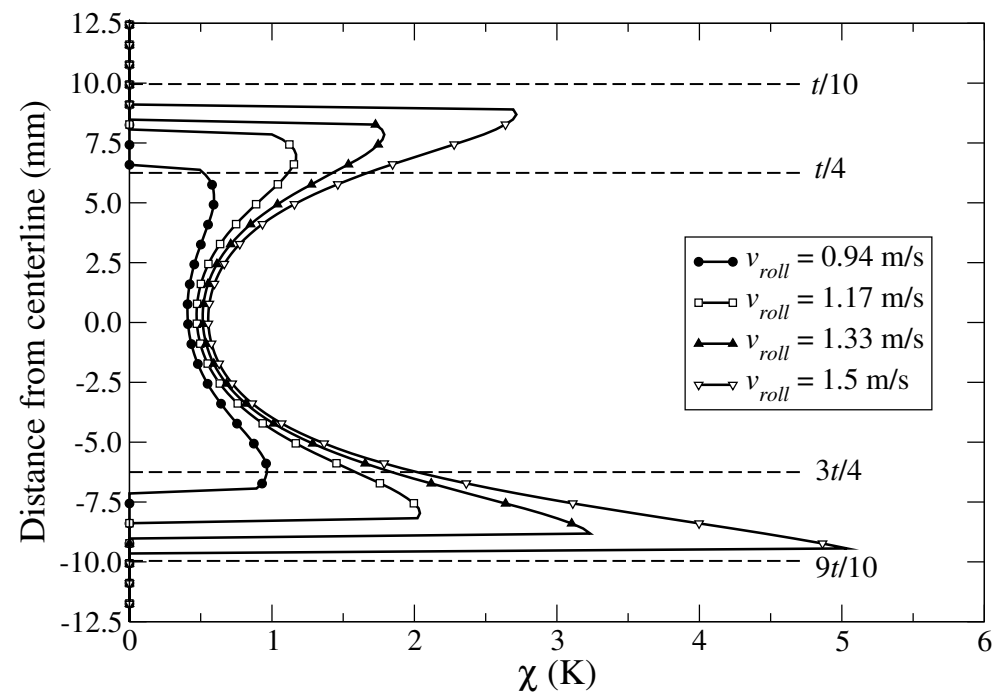

Figure 22: $\chi$ damage parameter at roll exit for various roll speeds

\subsection{Discussion and Conclusion}

Microscopy and DSC results indicate significant presence of strengthening precipitates in the as-received material. Industrial processing includes a homogenization at $480^{\circ} \mathrm{C}$ prior to hot rolling, which dissolves all but $\mathrm{Al}_{3} \mathrm{Zr}$ secondary phases. The $\mathrm{Al}_{3} \mathrm{Zr}$ particles act as inhibitors to recrystallization during hot deformation.

Isothermal compression tests were performed on AA705X specimens first homogenized at $480^{\circ} \mathrm{C}$, then cooled/heated to various temperatures ranging from $380^{\circ} \mathrm{C}$ to $500^{\circ} \mathrm{C}$, at nominal strain rates of $10^{-3} \mathrm{~s}^{-1}$ and $1 \mathrm{~s}^{-1}$. The material saturates at strains of approximately $2.5 \%$, so we may use the saturation stress to describe the material response under hot rolling conditions. The correlation of saturation stress with temperature compensated strain rate yields three distinct regions corresponding to Harper-Dorn creep $(n=1.2)$, five power law creep $(n=4.6)$, and a high stress region $(n=10.2)$. Microscopy on post compression specimens illustrates the possible onset of damage at $460^{\circ} \mathrm{C}$ and the progression to significant microdamage at $500^{\circ} \mathrm{C}$, thus fixing an upper limit to the TPW.

The derived mechanical constitutive relation has been implemented into a numerical rolling model as a non-Newtonian viscosity. Model parameters, such as roll slip coefficients and heat transfer coefficients, were tuned through comparison of simulated and experimental textures. Simulated texture was shown to be relatively insensitive to heat transfer coefficients and very sensitive to friction coefficients. Simulated textures were found to match quite well to experimental textures when asymmetric values of $\beta$ were used. Shear rate data illustrates the inhomogeneous deformation and asymmetry due to differential friction constants top and bottom.

The asymmetry induced by differential friction leads to localized shearing in the exit region that is greater near the bottom surface than the top for the final pass (Figure 14(d)). 
Deformational heating during hot rolling was shown to produce maximum temperatures above those at which damage was observed in mechanical testing. This suggests (qualitatively) the potential for sub-surface damage near the plate bottom. Looking forward, the collective effort:

- microscopic and mechanical documentation of homogenized structure,

- experimental identification of conditions leading to the onset of damage,

- and exercise of a rolling model with specification of boundary conditions consistent with evolution of material state

forms the basis for quantitative study of damage through introduction of appropriate evolutionary relations. 


\section{Products}

- The modeling framework is built upon a computational platform that is widely available, providing a tool for practical application in industry.

- Results of the modeling effort, specifically those results drawing the connection between mill set-up and the promotion of damage, have been presented to personel at both the industrial plant and research facility of our industrial collaborator.

- The work has resulted in two conference proceedings and two peer-reviewed publications:

- H. A. Padilla, S. F. Harnish, B. E. Gore, A. J. Beaudoin, J. A. Dantzig, I. M. Robertson, and H. Weiland, "High Temperature Properties and Processing of AA7055," Proceedings from Materials Solutions Conference 2003: 1st International Symposium on Metallurgical Modeling for Al Alloys, 2003, pp. 1-8.

- B. E. Gore, H. Padilla, B. J. Robinson, A. J. Beaudoin, J. A. Dantzig, I. M. Robertson, and H. Weiland, High Temperature Properties and Processing of AA7050, Hot Deformation of Aluminum Alloys III, TMS 2003, pp. 255-262.

- S. F. Harnish, H. A. Padilla, B. E. Gore, J. A. Dantzig, A. J. Beaudoin, I. M. Robertson, and H. Weiland, "High Temperature Behavior and Hot Rolling of AA705X," Metallurgical and Materials Transactions, 2005, vol. 36A, pp. 357369.

- B. G. Clark, I. M. Robertson, L. M. Dougherty, D. C. Ahn, and P. Sofronis, "High Temperature Dislocation-Precipitate Interactions in Al Alloys: An In-Situ TEM Deformation Study," Journal of Materials Research, 2005, vol. 20, no. 7, pp. 1792-1801.

- Presentations

H. A. Padilla "High temperature properties and processing of AA7055," Spring 2003, TMS Annual Meeting.

J. A. Dantzig High Temperature Deformation and Hot Rolling of AA7055," ASM meeting, 2003, Pittsburgh.

B. G. Clark "Microstructural Processes Occurring during Hot Deformation of AlZn-Mg-Cu-Zr," February 2003, Hot Deformation of Aluminum Alloys III, TMS 2003.

B. G. Clark "Dislocation Interactions in Aluminum Alloys: An In-Situ TEM Study," February 2004, Lawrence Livermore National Laboratory.

B. G. Clark "Dislocation-Particle Interactions in Al-4Mg-0.3Sc during In- Situ TEM Deformation Experiments at Elevated Temperature," February 2005, Langdon Symposium, TMS 2005. 
B. G. Clark "In-Situ TEM Observations of Dislocation-Particle Interactions during Elevated Temperature Deformation of Particle-Strengthened Al Alloys," to be presented November 2005, Symposium AA: Micro- and Nanomechanics of Structural Materials, MRS 2005.

- M.S. theses for Mr. H. Padilla and Mr. S. Harnish.

\section{Acknowledgments}

Microscopy presented in this work was performed in the Center for Microanalysis of Materials at the University of Illinois which is partially supported by the U.S. Department of Energy under grant DEFG02-91-ER45439. The load frame setup and compression platens were designed and built by Michael Bange. Dr. Hasso Weiland was the key point of contact with our industrial collaborator (Alcoa); he provided technical guidance and coordinated interchange between the university research effort and plant production personel. We are indebted to Mr. D. Ahn and Prof. Petros Sofronis of UIUC for their analysis of dislocation/particle interaction.

\section{References}

[1] S. F. Harnish, H. A. Padilla, B. Gore, J. A. Dantzig, A. J. Beaudoin, I. M. Robertson, and H. Weiland, "High-temperature mechanical behavior and hot rolling of aa705x," Metallurgical and Materials Transactions A, vol. 36A, pp. 357-369, 2005.

[2] B. G. Clark, L. Dougherty, I. Robertson, D. C. Ahn, and P. Sofronis, "High-temperature dislocation-precipitate interactions in al alloys: An in-situ transmission electron microscopy deformation study," Journal of Materials Research, vol. 20, pp. 1792-1801, 2005.

[3] S. M. Miyasato, G. H. Bray, J. Liu, and J. T. Staley, "Aluminum alloy products suited for commercial jet aircraft wing members." U.S. Patent 5,685,911, Feb 21999.

[4] D. Dumont, A. Deschamps, and Y. Brechet, "On the relationship between microstructure, strength and toughness in AA7050 aluminum alloy," Materials Science and Engineering A, vol. 356, pp. 326-336, 2003.

[5] D. Godard, P.Archambault, E. Aeby-Gautier, and G. Lapasset, "Precipitation sequences during quenching of the AA 7010 alloy," Acta Materialia, vol. 50, pp. 2319-2329, 2000.

[6] L. M. Dougherty, Mechanisms operating during continuous dynamic recrystallization in an Al-4Mg-0.3Sc alloy. PhD thesis, University of Illinois at Urbana-Champaign, 2001. 
[7] K. Fukunaga and Y. Miura, "Electron microscopic analysis of dislocation strucutres in $11_{2}$-al ${ }_{3}$ sc intermetallic compound," Journal of the Japan Institute of Metals, vol. 62, pp. 369-376, 1998.

[8] S. Iwamura, M. Nakayama, and Y. Miura, "Coherency between $a_{3}$ sc precipitate and the matrix in al alloys containing sc," Materials Science Forum, vol. 396-402, pp. 1151-1156, 2002.

[9] R. Hyland_Jr. and R. Stiffler, "Determination of the elastic constants of polycrystalline al $_{3}$ sc," Scripta Metallurgica et Materialia, vol. 25, pp. 473-477, 1991.

[10] Y. Harada and D. Dunand, "Thermal expansion of $\mathrm{al}_{3} \mathrm{sc}$ and $\mathrm{al}_{3}\left(\mathrm{sc}_{0.75}, \mathrm{x}_{0.75}\right)$," Scripta Materialia, vol. 48, pp. 219-222, 2003.

[11] W. Pearson, A Handbook of Lattice Spacings and Structures of Metals and Alloys, vol. 2. Pergamon Press, 1967.

[12] ASM Metals Handbook. Properties and Selection: Nonferrous Alloys and Pure Metals, vol. 2. American Society for Metals, 1979.

[13] E. Orowan, "The calculation of roll pressure in hot and cold flat rolling," Proc. Inst. Mech. Eng., vol. 150, pp. 140-167, 1943.

[14] A. I. Fedoseev and G. Gottstein, "Inhomogeneous deformation and texture during rolling," in Proceedings of the 1st Internation Conference on Modelling of Metal Rolling Processes, (London), pp. 296-308, The Institute of Metals, 1993.

[15] B. Beckers, R. Sebald, G. Pomana, D. Gade, and G. Gottstein, "Interactive textureand finite-element-simulations for modelling of complex deformation processes," in Proceedings of the 19th Risø International Materials Science: Modelling of Structure and Mechanics of Materials from Microscale to Product, (Roskilde, Denmark), pp. 219-227, Risø National Laboratory, 1998.

[16] O. Engler, E. Sachot, J. C. Ehrstrom, A. Reeved, and R. Shahani, "Recrystallisation and texture in hot deformed aluminium alloy 7010 thick plates," Mater. Sci. Technol., vol. 12, pp. 717-729, 1996.

[17] M. L. Lovato. Personal communication. Los Alamos National Laboratory Materials Science Technician 6 .

[18] E. Cerri, E. Evangelista, A. Forcellese, and H. J. McQueen, "Comparative hot workability of 7012 and 7075 alloys after different pretreatments," Mat Sci Eng, vol. A197, pp. 181-198, 1995.

[19] T. Sheppard and D. S. Wright, "Determination of flow stress: Part 1 constitutive equation for aluminum alloys at elevated temperatures," Metals Technology, vol. June, p. 215, 1979. 
[20] M. E. Kassner and M.-T. Peréz-Prado, "Five-power-law creep in single phase metals and alloys," Progress in Materials Science, vol. 45, no. 1, 2000.

[21] Y. P. Varshni, "Temperature dependence of the elastic constants," Phys Rev B, vol. 2, pp. 3952-3958, 1970.

[22] E. Brandes and G. Brook, eds., Smithell's Metals Reference Book: 7th Edition, pp. 1316. Oxford: Butterworth, 1992.

[23] A. Ghosh, Atlas of Stress-Strain Curves, ch. Nonferrous Metals, p. 443. Metals Park, Ohio: ASM International, 2002.

[24] F. V. Giardina, "Mechanical test report," 1992. Reynolds Metals Company.

[25] T. Sheppard, P. J. Tunnicliffe, and S. J. Patterson, "Direct and indirect extrusion of a high strength aerospace alloy (AA7075)," J Mech Work Tech, vol. 6, pp. 313-331, 1982.

[26] G. E. Dieter, Mechanical Metallurgy Third Edition. New York, NY: McGraw-Hill, Inc., 1986.

[27] E. Kovács-Csetényi, N. Q. Chinh, and I. Kovács, "Effect of microstructure on the hot deformation characteristics of aluminium alloys," Materials Science Forum, vol. 217222, pp. 1175-1180, 1996.

[28] W. Hander, G. Sarma, and P. Dawson, "Compression testing of 7050 aluminum at elevated temperatures." Cornell University, Ithaca, New York, December 1984.

[29] K. K. Mathur and P. R. Dawson, "On modeling the development of crystallographic texture in bulk forming processes," International Journal of Plasticity, vol. 5, no. 1, pp. 67-94, 1989.

[30] K. K. Mathur and P. R. Dawson, "On modeling the development of crystallographic texture in bulk forming processes," Intl J Plasticity, vol. 5, pp. 67-94, 1989.

[31] L. A. Lalli. Personal communication. Alcoa, Inc.

[32] A. A. Tseng, S. X. Tong, S. H. Maslen, and J. J. Mills, "Thermal behavior of aluminum rolling," Journal of Heat Transfer, vol. 112, pp. 301-308, May 1990.

[33] C. O. Hlady, J. K. Brimacombe, I. V. Samarasekera, and E. Hawbolt, "Heat transfer in the hot rolling of metals," Metallurgical and Material Transactions B, vol. 26B, pp. 1019-1027, October 1995.

[34] R. Lebensohn and C. N. Tomé, "A self-consistent anisotropic approach for the simulation of plastic deformation and texture development of polycrystals: Application to zirconium alloys," Acta Metallurgica et Materialia, vol. 41, pp. 2611-2624, 1993. 
[35] O. Engler, M.-Y. Huh, and C. N. Tomé, "A study of through-thickness texture gradients in rolled sheets," Metallurgical and Material Transactions A, vol. 31, pp. 2299-2315, September 2000.

[36] B. Hum, H. Colquhoun, and J. Lenard, "Measurements of friction during hot rolling of aluminum strips," J. Mat. Proc. Tech., vol. 60, pp. 331-338, 1996.

[37] M. Chun and J. G. Lenard, "Hot rolling of an aluminum alloy using oil/water emulsions," J. Mat. Proc. Tech., vol. 72, pp. 283-292, 1997. 